\title{
"El clima laboral en la empresa constructora CARMOR, del municipio y departamento de Jalapa"
}

\section{"The work environment in the construction company CARMOR, of the municipality and department of Jalapa "}

\section{Como citar el artículo}

Aragón, H. (2020). El clima laboral en la empresa constructora CARMOR, del municipio y departamento de Jalapa. Revista Naturaleza, Sociedad y Ambiente, 7 (1), 103-128. DOI: https://doi.org/10.37533/cunsurori.v7i1.55

Hugo Jovany Aragón González

\section{Centro Universitario de Sur Oriente, Universidad de San Carlos de Guatemala}

Recibido: 14 de abril de 2020 / Aceptado: 10 de septiembre de 2020

Disponible en internet el 10 de noviembre de 2020

*Autor para correspondencia, correo electrónico: jovanyaragon@gmail.com

\begin{abstract}
Resumen
El presente artículo sobre el estudio de caso realizado en la empresa constructora CARMOR del municipio y departamento de Jalapa, tiene como objeto principal exponer el compendio de datos sobre el clima laboral en la mencionada empresa. Se ha analizado cómo el manejo de la empresa influye en el comportamiento de sus empleados y poder determinar el grado de satisfacción laboral que ellos manifiestan. Para la obtención de esta información, se han tomado en cuenta temas importantes y de utilidad para diagnosticar los niveles en que se presentan las dimensiones del clima laboral. Los resultados obtenidos indican que el clima laboral no es completamente satisfactorio, puesto que existen ciertos parámetros que se han descuidado por parte de la organización, por lo que es necesario desarrollar e implementar en las áreas detectadas con alguna falla, estrategias de mejora en las insatisfacciones laborales encontradas.
\end{abstract}

Palabras clave: clima laboral, motivación, comunicación, liderazgo, satisfacción laboral

\begin{abstract}
The present article on the case study carried out in the company constructor CARMOR of the municipality and department of Jalapa, has as main object to expose the compendium of data on the work environment in the mentioned company. It has been analyzed how the management of the company influences the behavior of its employees and to determine the degree of job satisfaction they manifest. In order to obtain this information, important and useful topics have been taken into account to diagnose the levels at which the dimensions of the working environment are presented. The results obtained indicate that the work environment is not completely satisfactory, since there are certain parameters that have been neglected by the organization, so it is necessary to develop and implement in the areas detected with some failure, strategies for improvement in dissatisfactions labor found.
\end{abstract}

Keywords: work climate, motivation, communication, leadership, job satisfaction 


\section{Introducción}

En la actualidad las empresas desean brindar los mejores servicios, para lo cual necesitan el personal adecuado y capacitado para la ejecución de cada una de las actividades que se requieran, lo que se logra mediante un clima laboral adecuado. En Guatemala como en el mundo entero, las empresas enfocan sus esfuerzos en brindar productos y/o servicios de la mejor calidad, para poder lograr una aceptable participación competitiva en el sector donde se encuentran. Es importante recalcar que para el logro de dichos objetivos es necesario contar con el capital humano, quienes serán los encargados de realizar dichas actividades, poniendo en práctica técnicas y actitudes necesarias, aportando así a la empresa sus conocimientos y habilidades para generar ambientes agradables dentro de la organización.

La presente investigación tuvo como objetivo principal el análisis de los factores que afectan el clima laboral en la empresa constructora CARMOR , ubicada en el municipio y departamento de Jalapa. Siendo una investigación de tipo descriptivo, como fuente se presentan antecedentes de investigaciones sobre el clima laboral y un marco teórico en donde se incluye información sobre los indicadores utilizados, los cuales fueron: motivación, comunicación, liderazgo y satisfacción laboral. Los sujetos de estudio fueron 122, los cuales estaban conformados por 14 en el nivel administrativo y 108 en el nivel operativo. El instrumento utilizado para la recolección de información fue el cuestionario, con una escala que abarcó los criterios: nunca, algunas veces, frecuentemente y siempre.

Se logró concluir que el clima laboral de la empresa constructora CARMOR, es parcial- mente favorable, con las observaciones que, siempre existirán algunos empleados que no se sienten a gusto ni motivados con el trabajo que están desempeñando por situaciones de contratación, de incentivos, prestaciones y jornadas laborales. Por ello, es necesario fortalecer el indicador motivación, lo cual se puede realizar mediante un programa de reconocimientos y alicientes para el personal, recordando que la buena comunicación, las relaciones personales, el gusto por el trabajo, buena remuneración y la fomentación de desarrollo en los trabajadores, son factores importantes que influyen en el clima laboral e incrementan la productividad de la empresa.

\section{Referente teórico Clima laboral}

Katz y Kahn (1989), afirman que toda organización crea su propia cultura o clima organizacional. El clima o cultura refleja las normas y valores del sistema formal y la manera en que los interpreta el sistema informal. También es un reflejo de la historia de las luchas internas y externas, los tipos de personas que la organización atrae, sus propios procesos laborales, las formas de comunicación y como se practica la autoridad dentro del sistema. Robbins y Judge (2009), se refieren al clima laboral como la manera en que las personas actúan dentro de las organizaciones, encierra el impacto de los individuos, grupos y estructuras y que de él depende la conexión del sistema social.

Por otra parte, Chiavenato (2009), aborda al clima laboral en el contexto de los procesos de motivación dentro de los espacios organizacionales. Las personas se adaptan continuamente a diversas situaciones para satisfacer sus necesidades y mantener el equilibrio emocional. Para Méndez (2006), 
el origen del clima laboral está en la sociología; el concepto de organización dentro de la teoría de las relaciones humanas, destaca la importancia del hombre en la función del trabajo y la participación en un sistema social. El clima o comportamiento organizacional, es el estudio que se ocupa de las gestiones de los trabajadores.

\section{Motivación}

Según Ardouin et al., (2000), la motivación puede definirse como la voluntad que tienen los individuos para realizar esfuerzos hacia las metas que tienen las organizaciones, satisfaciendo al mismo tiempo necesidades individuales. Es de importancia en los colaboradores de una compañía, puesto que ellos darán todo de sí en pro de un objetivo organizacional y personal, aportando ideas creativas e innovadoras a la empresa. McGregor (1966), hace mención que en algunas ocasiones sucede que, aunque la necesidad no se satisfaga, tampoco existe frustración pues se transfiere a otra necesidad. Puede deducirse, que la motivación tiene diferentes niveles de estructura y desarrollo.

El clima laboral está ligado con la motivación, si los trabajadores están motivados el clima laboral es alto y proporciona satisfacción, animación, interés y colaboración entre el personal. Por su parte, García (2007), argumenta que si la motivación para los empleados es baja, existe frustración y se sienten insatisfechos, lo cual deteriora el ambiente interno de la institución. Es el deseo de esforzarse por alcanzar las metas, con la finalidad de satisfacer alguna necesidad individual. Debe entonces, concentrarse en metas a fin de reflejar el interés primordial por el comportamiento ligado con la motivación y el sistema de valores que rige la organización.

\section{Comunicación}

Amoros (2007), explica que es lógico que ningún grupo pueda existir sin la comunicación, entendiéndose ésta como la trasmisión y el entendimiento del significado. Con este punto de vista, es importante entender que una empresa no funciona si no existe una comunicación entre sus miembros. Tiene como base las redes de comunicación que existen dentro de la organización, así como la facilidad que tienen los empleados de hacer que sus comentarios sean escuchados y tomados en cuenta. La comunicación brinda un medio para la expresión emocional de los sentimientos y para satisfacer las necesidades sociales.

Proporciona información que los individuos y grupos necesitan para tomar decisiones por medio de la transmisión de datos. Adler (2005), indica que todos los colaboradores se comunican, sin importar cuál sea el campo de acción o cuanto se conozca el tema, el conocimiento especializado no es suficiente para alcanzar el éxito. Las habilidades para comunicarse son relevantes, puesto que una gestión eficaz y eficiente de la comunicación tiene mucho que decir en el momento de crear valor en las organizaciones, inmersas en un acelerado y competitivo mundo empresarial.

\section{Liderazgo}

Blanchard (2000), afirma que el liderazgo es la capacidad de influir en los demás por medio de la manifestación del poder y el potencial de las personas y organizaciones, para lograr mayores intereses. James y Lindsey (2008), definen al liderazgo como la habilidad de influir positivamente en la gente y los sistemas bajo la autoridad de uno a fin de tener un impacto significativo y lograr resultados importantes. El liderazgo permite a un gerente 
obtener una participación activa y consciente en la consecución de los objetivos institucionales. Por tal razón, debe crear un ambiente propicio, estable y tranquilo para que los colaboradores se desarrollen de forma satisfactoria para el bienestar de la empresa.

Sallenave (1994), resalta que la habilidad del liderazgo, es la capacidad para comprender que los seres humanos tienen diferentes fuerzas motivadoras, en distintos momentos y en diversas situaciones; habilidad para inspirar, y la fuerza para actuar de forma tal, que establezca un clima laboral apropiado, para responder y para despertar motivaciones, al implementar un estilo de liderazgo que integre el buen trato y respeto por las personas. Para Espinoza (1999), los directivos tienen que ser estrategas, organizadores y líderes. Es la capacidad que tiene una persona de formular planes de éxito y de motivar a los demás para que se lleven a cabo, a pesar de las dificultades y riesgos que se tengan que enfrentar.

\section{Satisfactores del trabajo}

De acuerdo con Dessler (2009), los satisfactores son un conjunto de elementos que condicionan el estado de bienestar psicológico en el trabajo. Algunas personas lo asocian con la motivación en el trabajo, a través de compensaciones monetarias, estímulos psicológicos y bienestar derivado de la asociación y el contacto con otras personas. La satisfacción del trabajo no solo es derivada de la interacción con las personas con las que se tiene contacto directo y activo en un momento determinado, sino que también por contacto de con quienes se estuvo relacionado directamente y que ahora se relaciona indirecta y ocasionalmente.
Para Landy y Conte (2005), la presencia de insatisfactores en el trabajo puede disminuir el desempeño en el trabajo. Su impacto sobre el cometido en el trabajo, tiene mayor fuerza que la satisfacción. Esto indica que si se desea aumentar la productividad en el trabajo como consecuencia de la satisfacción laboral, se debe trabajar los factores específicos asociados a las condiciones de trabajo en donde se producen insatisfacciones. La importancia relativa de un aspecto laboral en particular para el trabajador, influye en sus respuestas a ese aspecto laboral, es decir, que si se valora más el elogio de un jefe que la admiración de los compañeros, la satisfacción general con la empresa se verá más fuertemente influida por sus interacciones con el jefe que con la de los compañeros. 
Figura No. 1 Modelo de los determinantes de la satisfacción

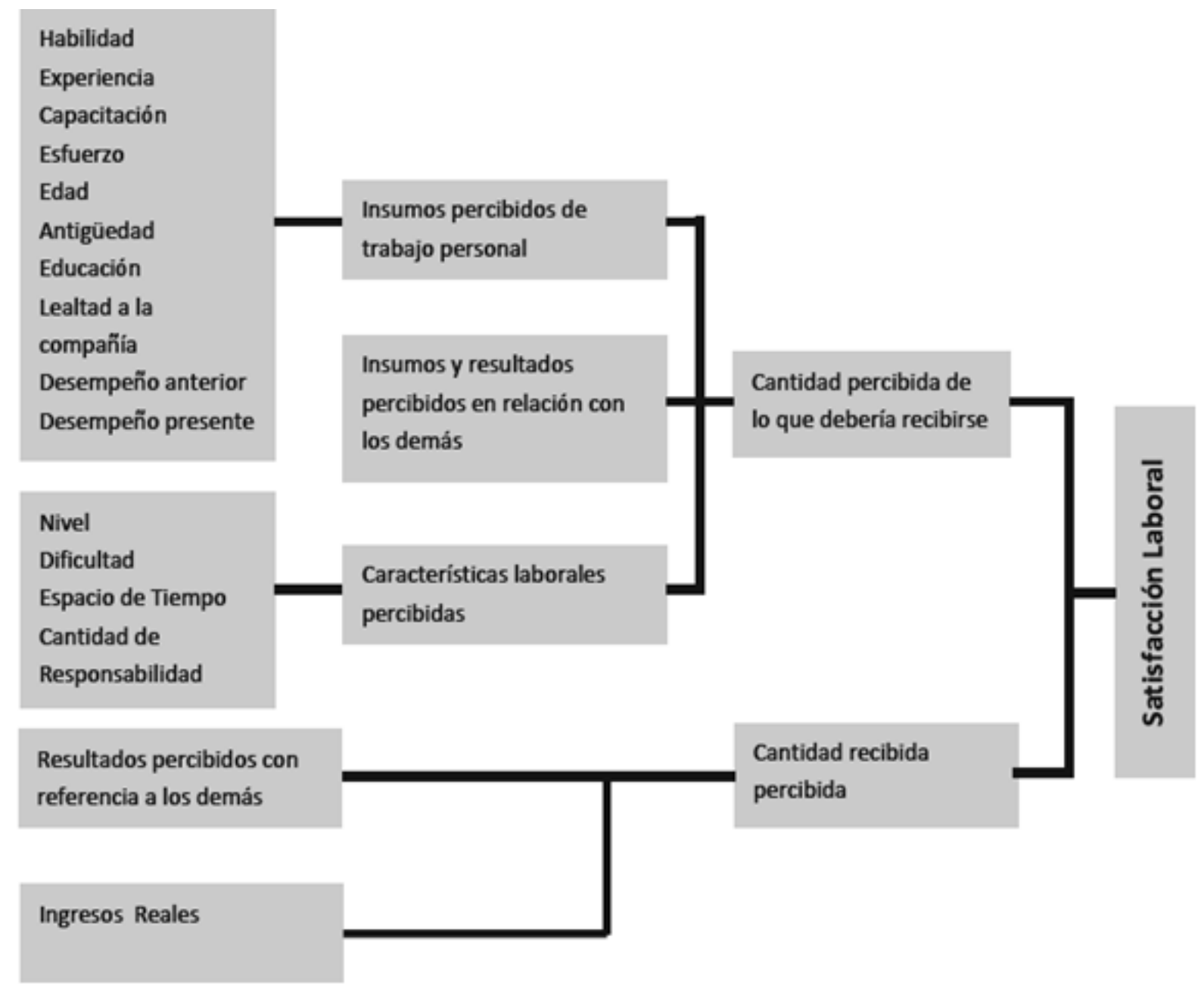

Fuente: Elaboración propia, con base a Landy y Conte (2005).

\section{Satisfacción laboral}

Según Robbins y Judge (2009), la satisfacción laboral se define como el pensamiento positivo respecto del trabajo propio, que resulta de una evaluación de sus características, representa una actitud en vez de un comportamiento. Rodríguez y Baker (2011), han encontrado una relación positiva con el rendimiento y la productividad, de modo que quienes están satisfechos con su trabajo presentan un mayor rendimiento y son más productivos. Las facetas de la satisfacción laboral son las siguientes: la satisfacción laboral propiamente dicha, la satisfacción con el salario, la satisfacción con los compañeros, la satisfacción con los jefes, y la satisfacción con los ascensos, cada faceta de la satisfacción en diferentes grupos contiene los elementos actitudinales de los componentes afectiva, cognitivo y del comportamiento. Adicionalmente se encontró que la relación entre la satisfacción laboral e inseguridad laboral, seguía siendo significativa después de tener en cuenta variables demográficas tales como la edad, permanencia en la organización y género. Para García (2007), es común pensar que hoy en día las empresas proporcionan espacios físicos de trabajo saludable, seguros, y cómodos y además proveer las 
herramientas para realizar su trabajo de la mejor manera posible. A medida que se investiga más sobre este aspecto se encuentra que aún las variaciones más modestas en temperatura, ruido, iluminación o calidad del aire, pueden ejercer efectos apreciables en el desempeño y las actitudes del empleado.

\section{Metodología}

Llevar a cabo una investigación implica considerar diferentes métodos, técnicas e instrumentos para la construcción del conocimiento científico. Esto significa un compromiso con la calidad del tipo de conocimiento que se produce.

\section{Método}

El estudio de casos es el método que fue utilizado para realizar la investigación del clima laboral en la empresa constructora CARMOR del municipio y departamento de Jalapa. Este proceso se caracterizó por analizar con profundidad el objeto y establecer cómo funcionan todas las partes que lo componen y las relaciones entre ellas, para formar un todo. En su realización se efectuó una encuesta de forma general en todas las áreas de la empresa, cubriendo el 83\% (122 trabajadores) de la población total; debido a que no se obtuvo el acceso a todos los empleados, porque algunos no se encontraban en la cabecera departamental de Jalapa, cumpliendo con sus labores en proyectos que la empresa realiza. Esto ocasionó que no se compartiera con todos los colaboradores de la constructora en las distintas áreas de trabajo, pero sí se logró trabajar con un alto porcentaje.

\section{Indagatoria}

Se llevó a cabo por medio de los procesos de recolección de información, directamente de las fuentes primarias (cuestionario a los empleados) y secundarias (libros y textos), de los cuales se obtiene los elementos necesarios para la elaboración del informe.

\section{Técnica}

Para la técnica de investigación, se utilizó una encuesta sobre el clima laboral para recolectar los datos, enfocada hacia la obtención de información acerca del compromiso y la satisfacción laboral de los colaboradores de la constructora en mención, dirigido al nivel administrativo, asistencial y operativo de la constructora CARMOR. Las 122 encuestas se distribuyen en las ocho áreas que cuenta la empresa, cubriendo de esta manera el $83 \%$ de la población total, con la que se midieron las variables siguientes:
a. Motivación.
b. Comunicación.
c. Liderazgo.
d. Satisfacción laboral.

\section{Instrumento}

El instrumento utilizado para la elaboración de la encuesta, fue un cuestionario, un formulario con un listado que contiene 15 preguntas que se formuló de idéntica manera para todos los encuestados con 4 diferentes opciones, con el cual se obtuvo información apegada a la realidad de los empleados de la empresa constructora CARMOR, para diagnosticar y analizar los datos adquiridos, que fueron de relevancia en la elaboración de las gráficas y la construcción de conclusiones y discusión de datos. Una de las ventajas de utilizar el cuestionario, es que se requiere relativamente de poco tiempo para reunir la información que se desea conseguir, especialmente en este caso, que es un grupo numeroso. Las 
cuatro diferentes opciones de cada pregunta, 2-Algunas veces contemplan los siguientes criterios: 3 - Frecuentemente 1 - Nunca 4 - Siempre

Tabla No. 1 Listado de colaboradores de la Constructora CARMOR

\begin{tabular}{|c|l|c|}
\hline No. & \multicolumn{1}{|c|}{ Área } & Cantidad \\
\hline 1 & Gerencia & 3 \\
\hline 2 & Recepción & 1 \\
\hline 3 & Diseño y planificación & 6 \\
\hline 4 & Jefe de operaciones & 1 \\
\hline 5 & Administración de proyectos & 3 \\
\hline 6 & $\begin{array}{l}\text { Maestros de obra (choferes, } \\
\text { operadores, peones, albañiles) }\end{array}$ & 117 \\
\hline 7 & Asistente de operaciones (mecánicos) & 14 \\
\hline 8 & Auxiliar de contabilidad & 2 \\
\hline & & 147 \\
\hline
\end{tabular}

Fuente: Elaboración propia, con base a información de la empresa.

\section{Resultados}

A continuación se presentan los resultados obtenidos de la investigación de campo realizada en la empresa constructora CARMOR, que reflejan las opiniones de los empleados del nivel administrativo y operativo, por medio del cuestionario "Clima laboral".

Figura No. 1 Motivación para realizar eficientemente las funciones

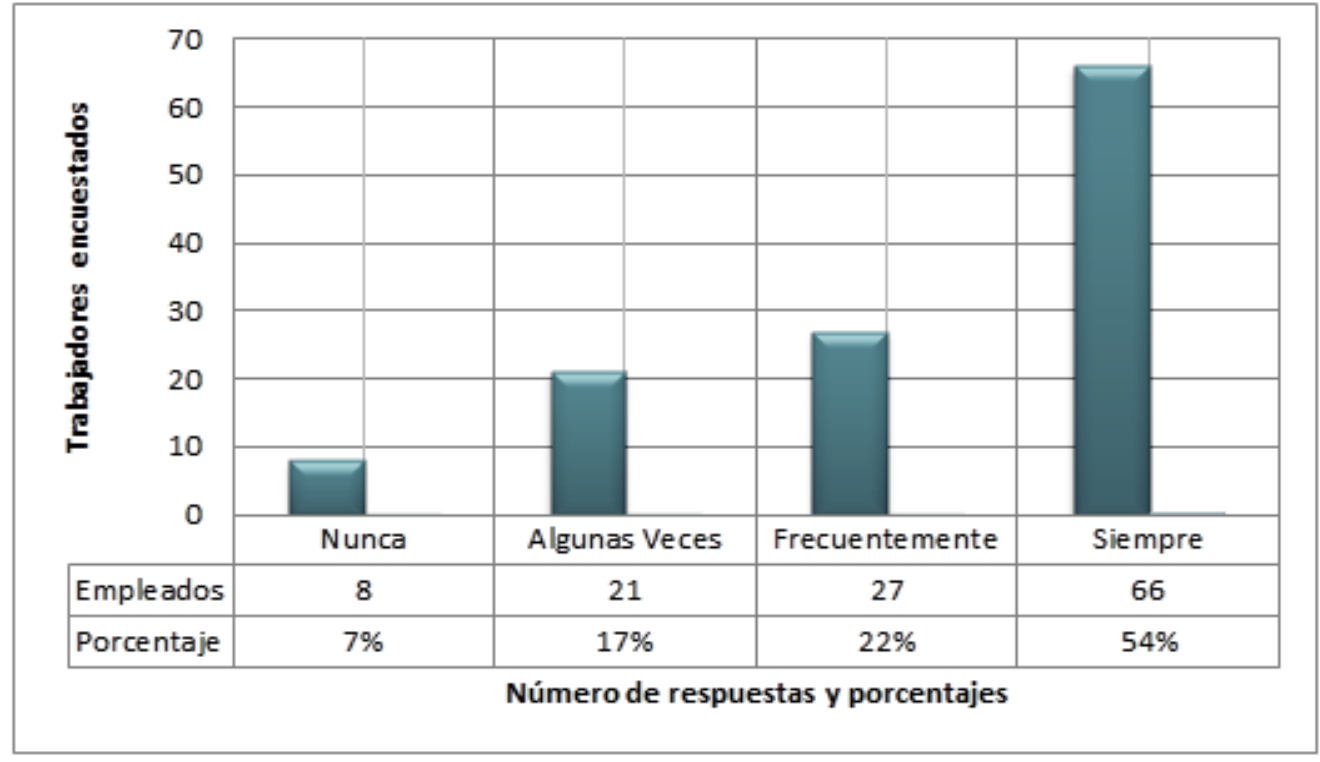

Fuente: Elaboración propia, con base a información de la empresa. 
La gráfica 1, indica que un $54 \%$ siempre está motivado dentro de la constructora. Existe un $22 \%$ que lo está frecuentemente, un $17 \%$ que lo manifiesta algunas veces, y un bajo porcentaje del $7 \%$ que nunca lo está. Estas cantidades deben analizarse puesto que no todos los empleados están altamente motivados en su labor y puede observarse que dentro de la constructora, existen causas que desmotivan a los empleados, como la falta de estímulos de diferentes tipos. En este punto, Robbins y Coulter (2005), hace notar que la motivación son todos los procesos responsables directamente del deseo de un individuo de realizar un gran esfuerzo para lograr objetivos organizacionales condicionados por la capacidad de satisfacer algún tipo de necesidades individuales. No siempre se logrará que los colaboradores realicen su trabajo con esfuerzo si estos no reciben la motivación necesaria por parte de los jefes.

Figura No. 2 Sentimiento de acogimiento entre compañeros de área

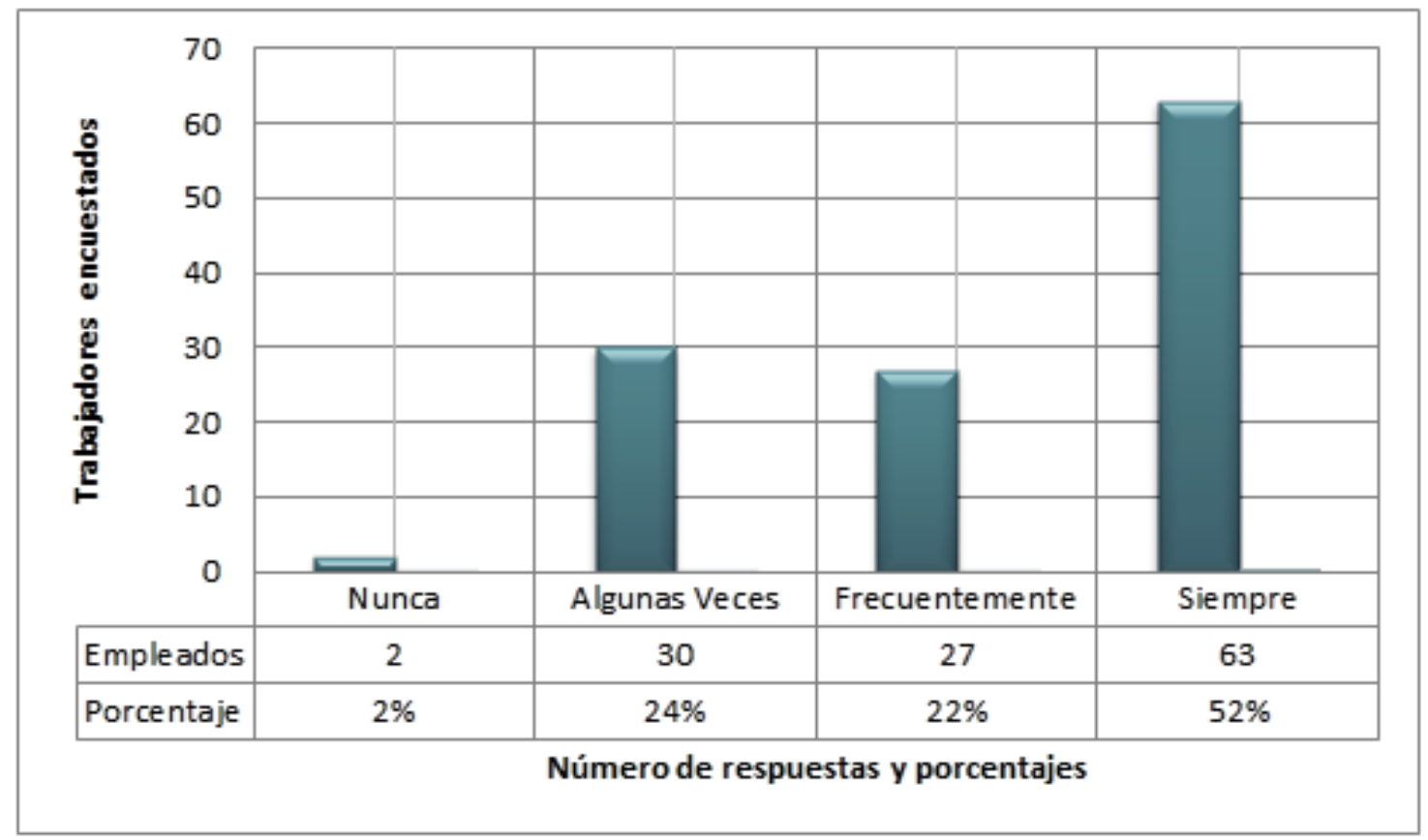

Fuente: Elaboración propia.

Se puede observar en la gráfica 2 , que un $52 \%$ de los empleados consideran que siempre existe buena relación con sus compañeros y con los superiores; un $22 \%$ perciben frecuentemente un acogimiento entre compañeros. El $24 \%$ de los encuestados piensan que algunas veces se han sentido bien recibidos en su área de trabajo, mientras que un $2 \%$ dicen que nunca han experimentado esta clase de relación armónica. Con estos resultados se puede deducir que dentro de la constructora existe un ambiente agradable para la mayoría, lo que hace que se facilite la convivencia, provocando que exista conformidad en el grupo de trabajo. Como lo dice García (2011), es importante tener en cuenta que la falta de comunicación genera problemas dentro de las organizaciones y torna difíciles los procesos. Por ello, la mayoría de los empleados logran los objetivos de cada departamento, al buscar trabajar en equipo y transmitir adecuadamente la información. 
Figura No. 3 Compatibilidad con el trabajo y los objetivos de la empresa

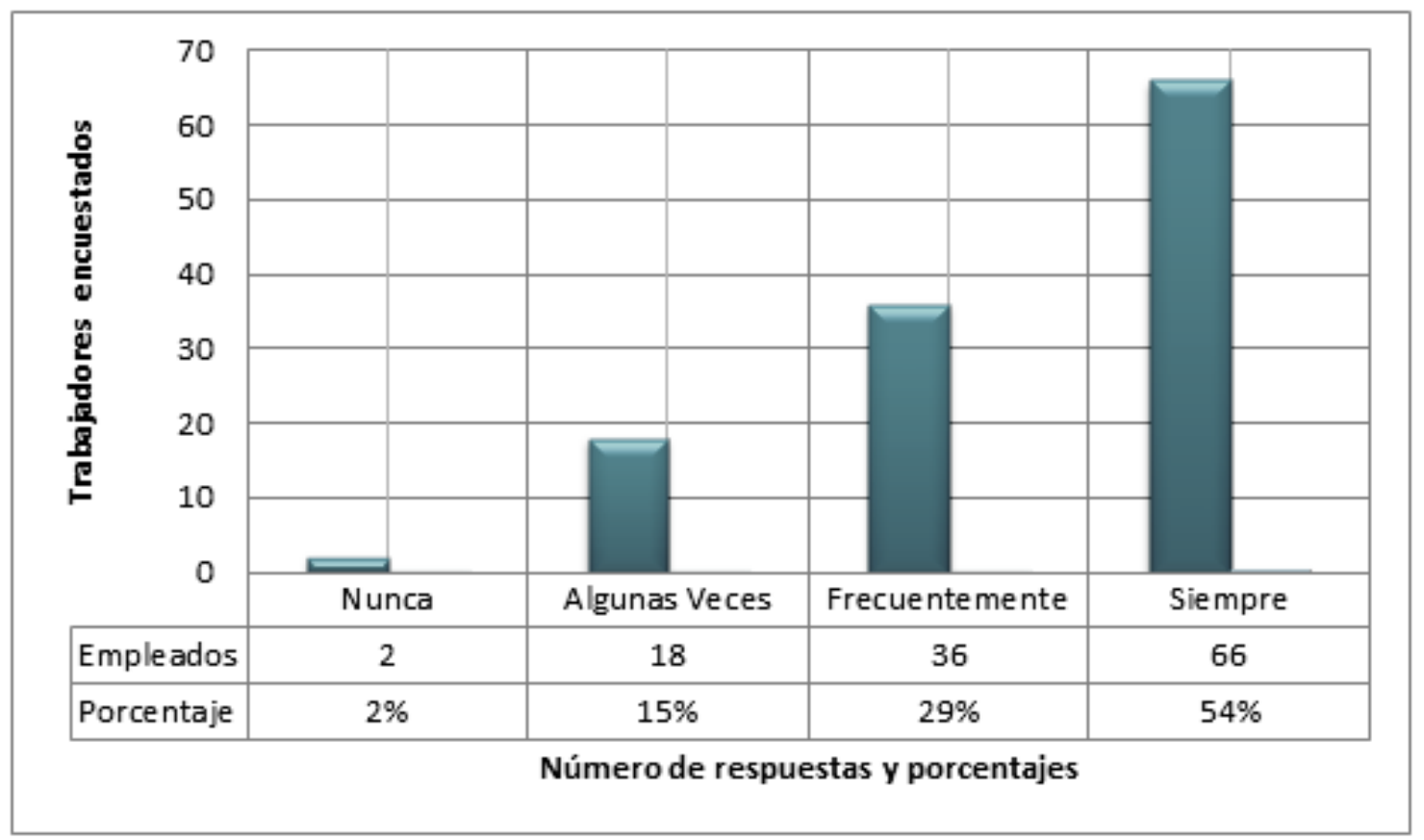

Fente: Elaboración propia.

El compromiso que cada colaborador tiene con la empresa, que es de suma importancia para el logro de las metas. La gráfica 3 muestra que un 54\% establece que siempre existe ese compromiso personal con la empresa para lograr cada uno de los objetivos establecidos; el $29 \%$ manifiesta que es frecuente su compatibilidad con lo que la empresa pretende. Un $15 \%$ de los empleados en algunas veces tienen un compromiso personal con la constructora, mientras que solamente un $2 \%$ de las personas encuestadas afirman que nunca han sido compatibles con la constructora. En este aspecto, es necesario señalar que aunque es muy bajo el porcentaje, existen personas que no se sienten parte de la empresa y su trabajo no tiene relación o vínculo alguno, un punto que para los objetivos de la empresa se convierte en un aspecto negativo. A ello se refiere Mitchell (1997), cuando aclara que en el centro de la teoría del establecimiento de metas se encuentra la idea de la acción con propósito. Las personas eligen las metas que se relacionan con la satisfacción de las necesidades, la aspiración y la búsqueda de deseos son parte central del proceso de la vida misma; por lo que la acción consciente y auto dirigida, es la responsable de casi todo lo que la gente hace. Por este motivo es que la constructora, en un alto porcentaje, cumple con sus objetivos gracias a los trabajadores que generalmente se encuentran motivados por parte de ella. 
Figura No. 4 Interés en los trabajadores por parte de jefes y supervisores

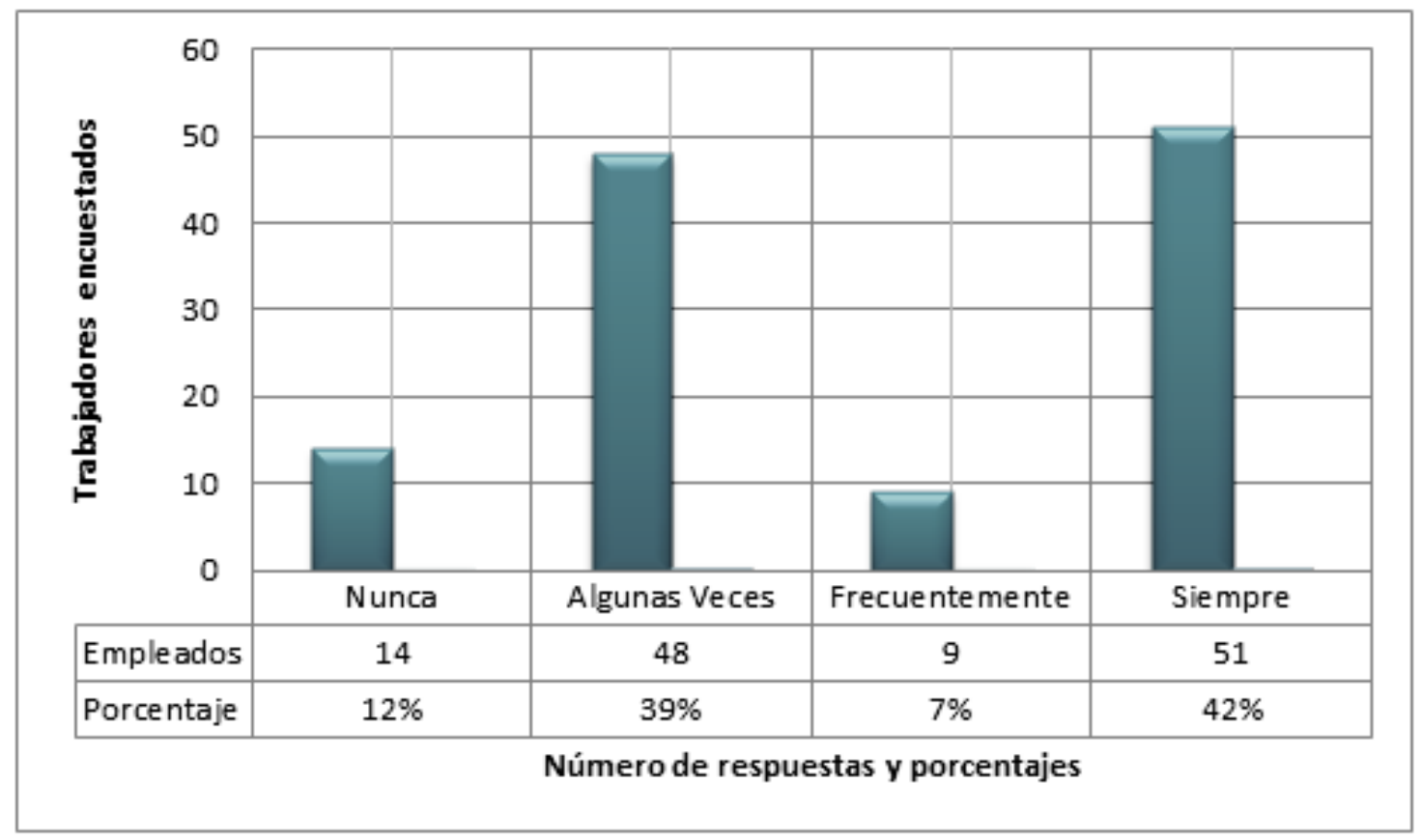

Fuente: Elaboración propia.

La interacción y la convivencia que existe entre jefe y empleado es un aspecto que debe de ser aplicado con ética y profesionalismo dentro de toda organización. Cada quien debe reconocer su cargo y por ende el puesto que le corresponde según el orden de jerarquía institucional. La gráfica 4 muestra que un $42 \%$ siempre sienten ese interés por parte de sus superiores. Solamente un $7 \%$ lo perciben frecuentemente, mientras que el $39 \%$ creen que en algunas veces hay muestras de interés por ellos, y un $12 \%$ aseguran que nunca lo han experimentado. En toda institución debe existir armonía y confianza entre jefe y empleado, para poder establecer bien los lazos de comunicación y estar al pendiente de qué es lo que necesitan los colaboradores, ya sea en materiales o recursos para que realicen su trabajo de una manera efectiva. Está claro que una parte considerable de los colaboradores no perciben ese interés por parte de sus jefes. Montes (2006), afirma que la mayoría de los trabajadores comprenden que es el supervisor quien a menudo controla el inicio y la longitud del intercambio, es decir que dependen de la actitud de las personas para poder interactuar con ellas. Existen personas que prefieren atención negativa a ser ignoradas, antes de que un supervisor o jefe se comunique con los trabajadores para impartirles las instrucciones laborales del día. 
Figura No. 5 Identificación positiva con el trabajo realizado

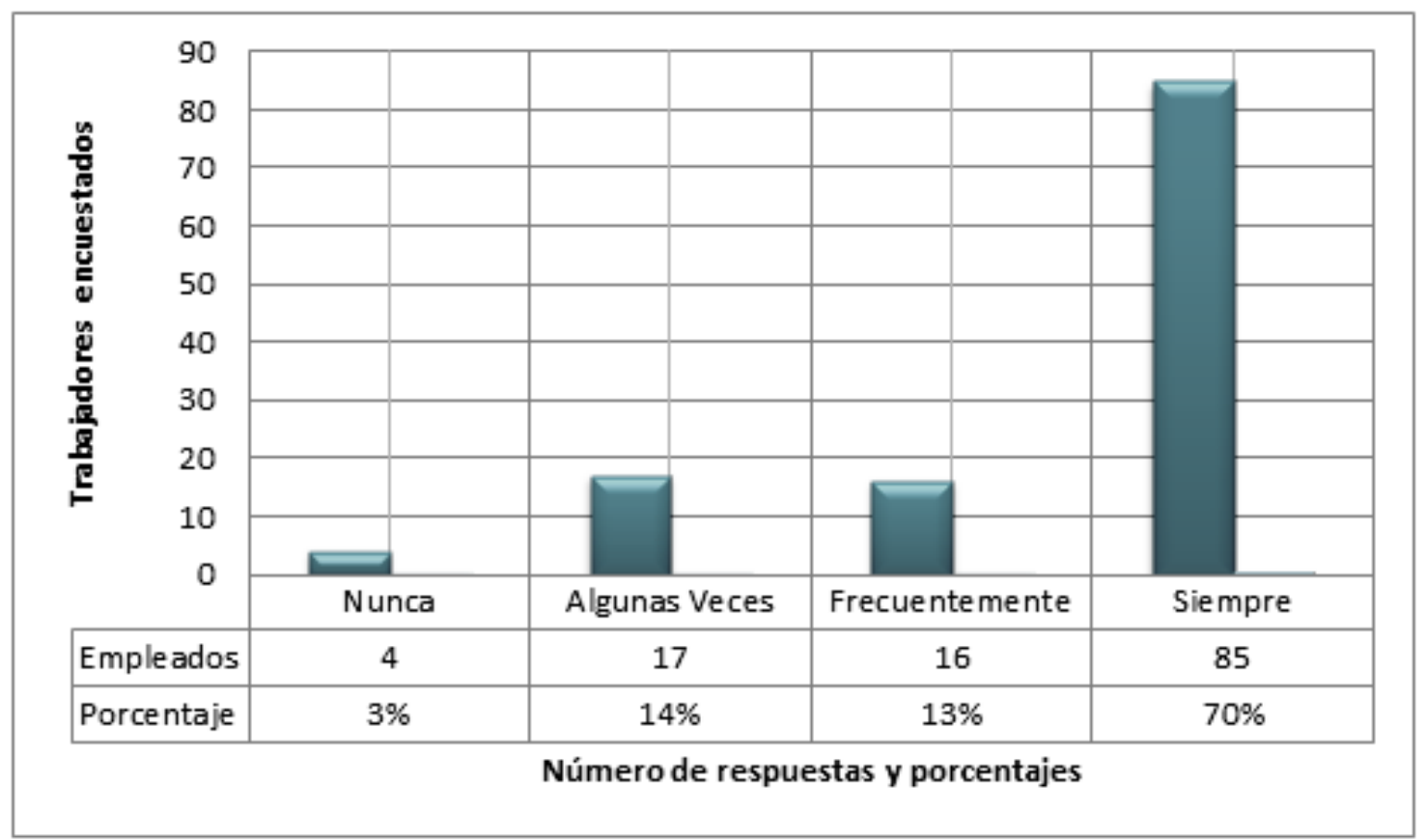

Fuente: Elaboración propia.

La gráfica 5 muestra una parte curiosa dentro de esta investigación, que el $70 \%$ de la población encuestada respondió siempre sentirse a gusto con su trabajo. El 13\% manifiesta que frecuentemente se identifica con su trabajo; el 14\% piensan que algunas veces se sienten cómodamente, mientras que un 3\% nunca están laborando con placer. Se dice que es curioso, porque según los resultados que muestran otras gráficas, un porcentaje considerable está pensando en otra clase de empleo. No es un porcentaje alto quien lo busca, pero sí existen algunas situaciones que pueden ser motivacionales que impulsen a algunos empleados a tomar estas decisiones. La constructora debe tomar importancia respecto al tema, como lo establece Cimpa (1990), que una empresa tiende a atraer y conservar personas que se adaptan a su clima. Los directivos deben percatarse de que el ambiente laboral forma parte del activo de la empresa, y como tal, deben valorarlo y prestar la debida atención, para lograr mayor tranquilidad y satisfacción por parte de los empleados. Debe considerarse también, que muchos de los colaboradores tienen tiempo laborando, lo que les induce a manifestar esa identificación laboral con la constructora, y que otros que inician en este trabajo, no se sienten completamente a gusto, o no se sienten cómodos en el área donde se desenvuelven. 
Figura No. 6 Recursos necesarios para poder desarrollar las funciones

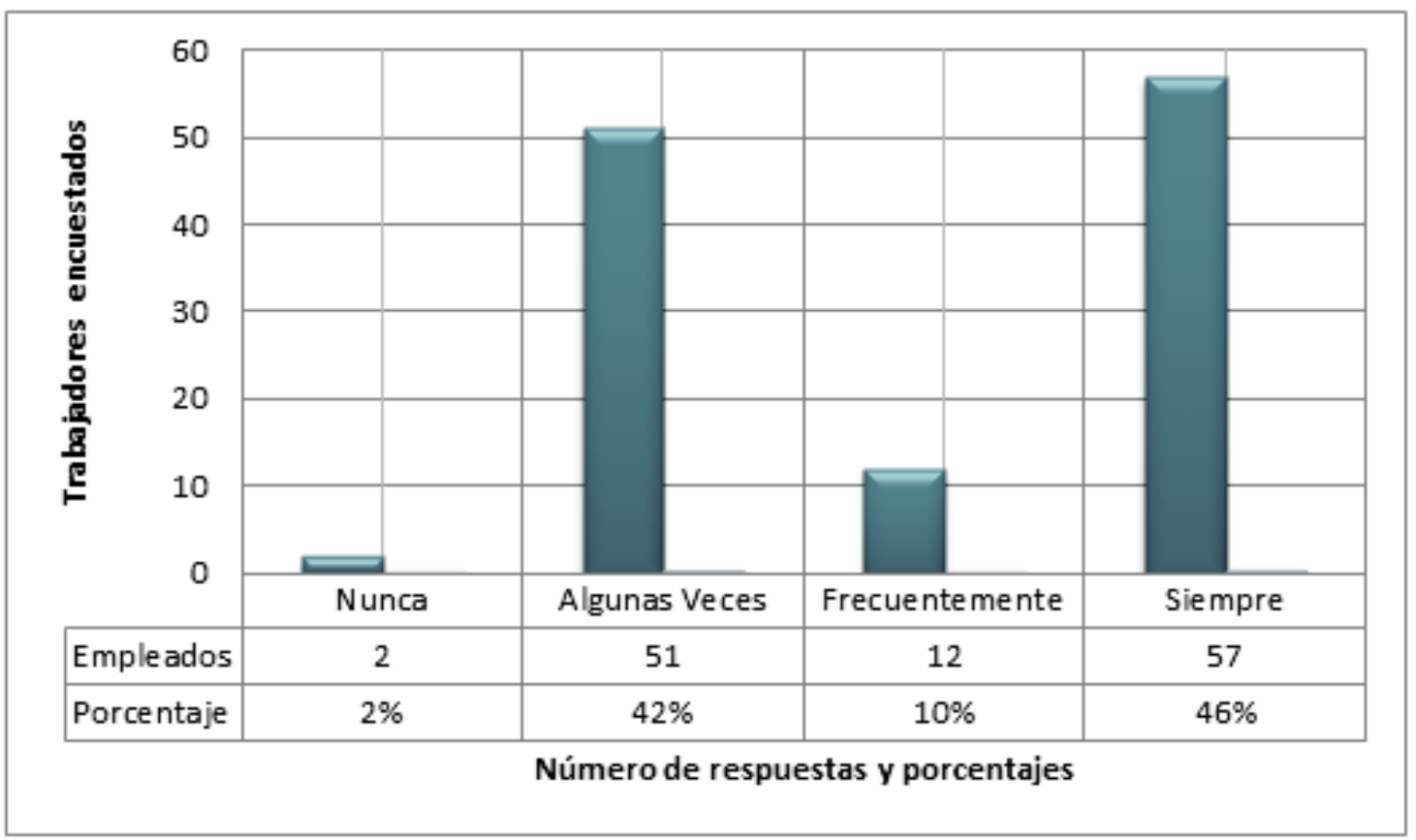

Fuente: Elaboración propia.

Puede observarse en la gráfica 6 que el $46 \%$ de las personas encuestadas dicen que siempre tienen los recursos necesarios en sus labores, mientras que un $10 \%$ aseguran que frecuentemente es que lo tienen. El $42 \%$ menciona que algunas veces sí lo tienen, y solamente el $2 \%$ respondieron que nunca tienen lo elemental para laborar. Este punto puede depender mucho del área o departamento donde se desenvuelven los empleados, pues dentro de las oficinas, la mayoría de personas cuentan con los recursos o herramientas necesarias para laborar, igualmente la mayor parte de los trabajadores de campo y los mecánicos. Lo que algunos colaboradores de campo expresan, es que no siempre tienen a tiempo los materiales o equipo para realizar sus labores. Según Lado y Wilson (1994), la diferencia en el rendimiento entre empresas se puede atribuir a la diferencia de recursos y capacidades existentes en las organizaciones. El objeto de cualquier empresa es generar una ventaja competitiva, con una rentabilidad superior a la de las empresas contendientes, por lo que utilizan recursos tangibles como intangibles en el desarrollo de sus estrategias. La situación en este marco apunta a que los jefes deben estar pendiente de su área de trabajo y que a sus subordinados no les falte o tengan a tiempo los instrumentos con los que elaborarán la tarea asignada. 
Figura No. 7 Actividades recreativas dentro de la constructora

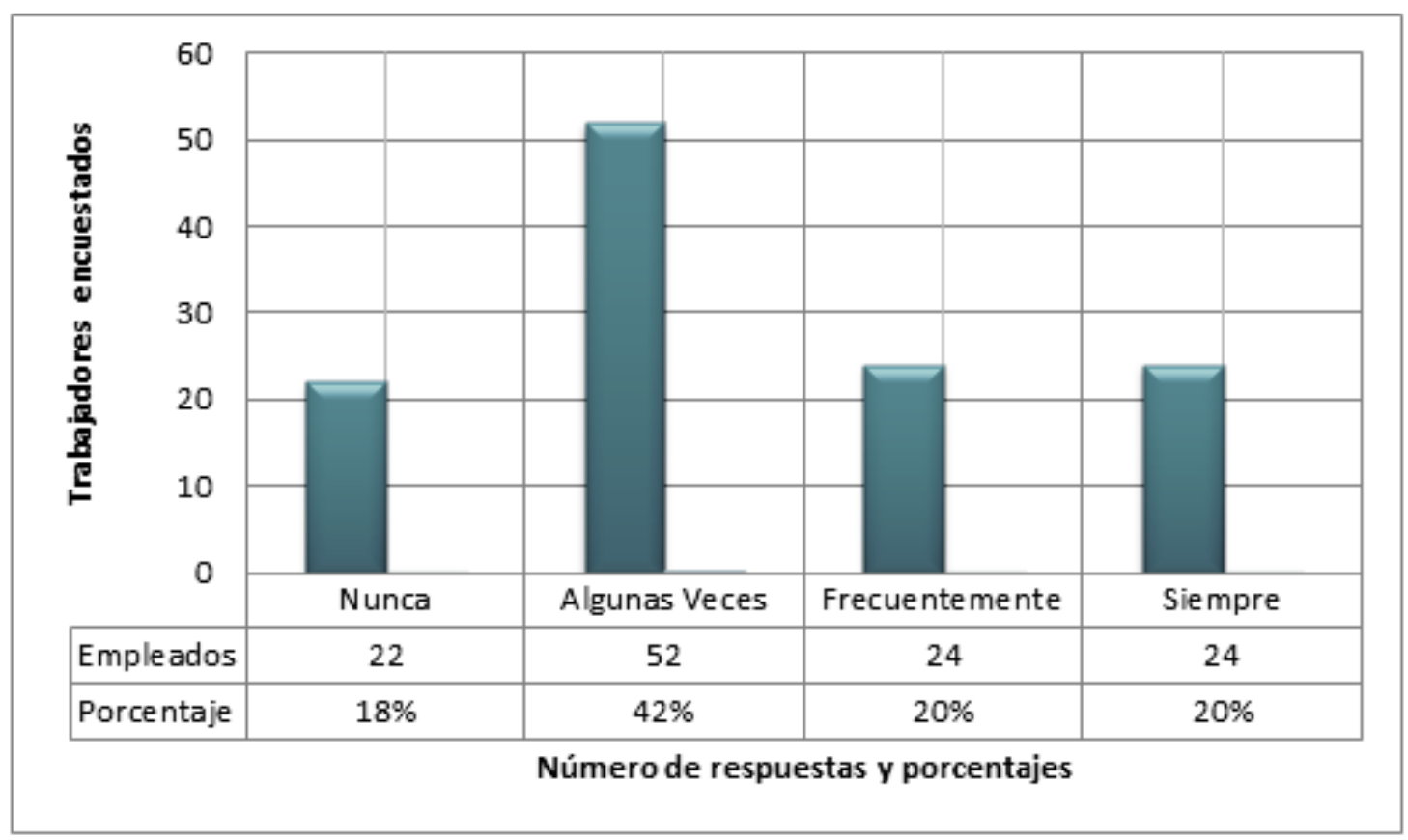

Fuente: Elaboración propia.

En la constructora puede observarse según la gráfica 7 , que no está definido a qué es lo puede nombrarse exactamente para todos los empleados, las actividades recreativas. Según pláticas con las personas de oficina, con quienes más contacto personal se mantuvo, mencionaron que celebraciones de cumpleaños y reconocimientos laborales o de estudios, sí se han realizado, pero que no se dan con tanta frecuencia. Por eso es que un $20 \%$ dice que siempre se realizan estas actividades, otro $20 \%$ indica que frecuentemente se llevan a cabo. El $42 \%$ menciona que en algunas veces se dan estas acciones, y el $18 \%$ aluden que nunca se ejecutan. Para Torres y Agulló (2002), la vida laboral se ve afectada no solo por factores intrínsecos al trabajo, sino también por todo lo que acontece en otras áreas extra laborales que conforman la vida diaria de los individuos, en este caso, las actividades recreativas. Los empleados de campo comentaron que por no estar presentes en ese momento, se pierden de esas diligencias, pero actividades recreativas que realmente sean utilizadas para motivar, agradecer o premiar a los trabajadores en general, no se realizan dentro de la constructora. La búsqueda de una vida laboral armoniosa, debe coincidir con los objetivos y metas de las empresas, para que de esta manera, lograr una estabilidad en el trabajo, beneficiando la productividad y eficiencia para ambas partes. 
Figura No. 8 Comunicación con superiores para solución a problemáticas

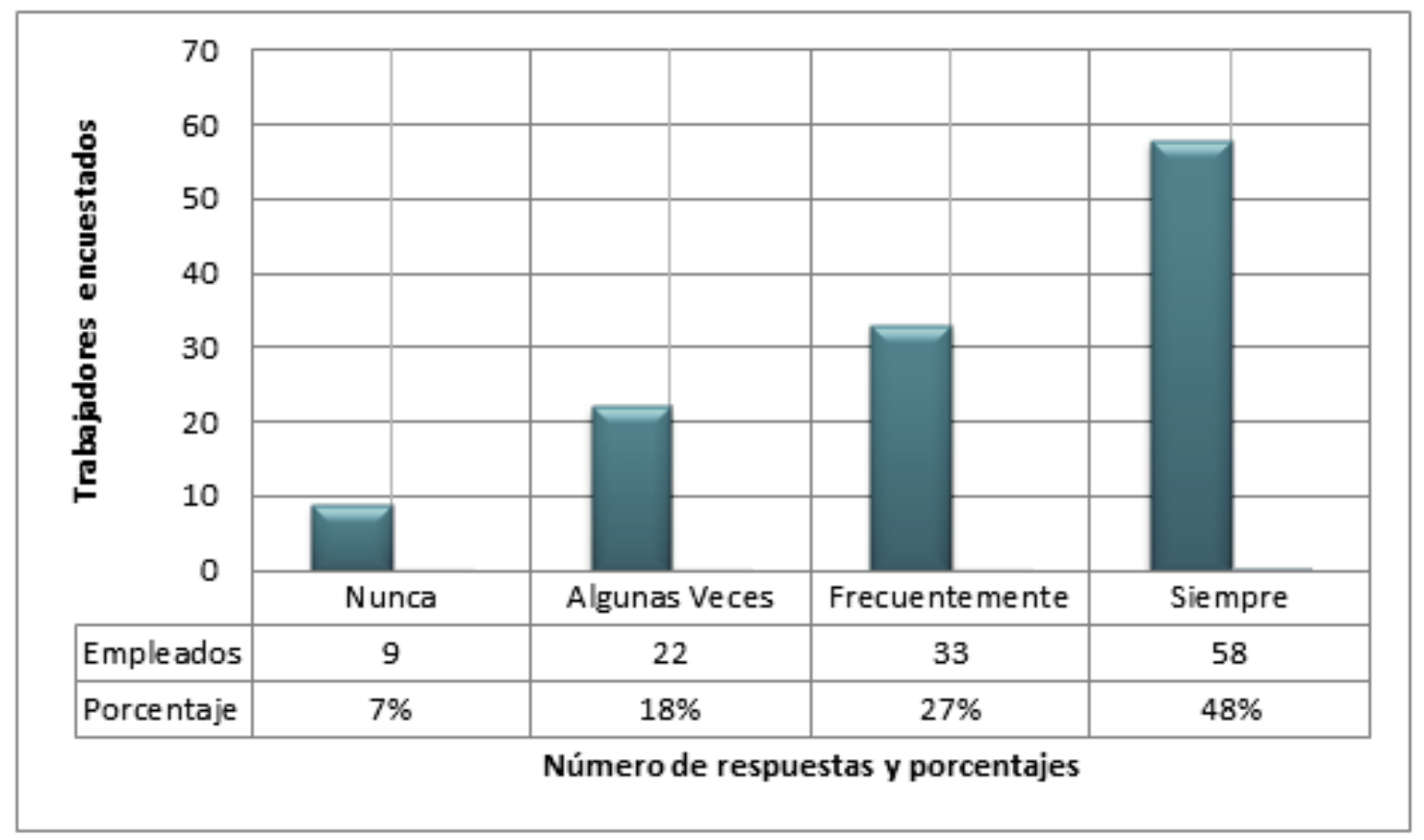

Fuente: Elaboración propia.

En la gráfica 8 , se refleja que un $48 \%$ de los empleados consideran que siempre pueden buscar el punto de vista de sus superiores o expresar algunas consultas con ellos. El $27 \%$ expresan que esto se da frecuentemente, mientras que el $18 \%$ opina que en algunas veces pueden tener esta comunicación, y el $7 \%$ afirman que nunca lo han establecido. Esto conduce a que algunos colaboradores se sientan satisfechos al ser escuchados, porque pueden preguntar, decir ideas y buscar mejorar en beneficio de la institución. Carretón (2007), hace referencia a que el boletín informativo o revistas, son los medios impresos más utilizados por las empresas, para mantener una relación informativa bidireccional con los trabajadores. Por tal razón, los colaboradores señalan que los medios escritos que se utilizan en la constructora, son eficaces para el traslado de la comunicación, puesto que las notificaciones de los altos mandos llegan a todo el personal. Pero existen también los trabajadores que indican que no tienen la confianza con el directivo de comentarle los problemas personales que afectan el rendimiento en el trabajo, con el fin de buscar soluciones y controlar las emociones; lo que puede provocar un mal desempeño y afectar a la organización. 
Figura No. 9 Satisfacción de los empleados con el puesto que desempeñan

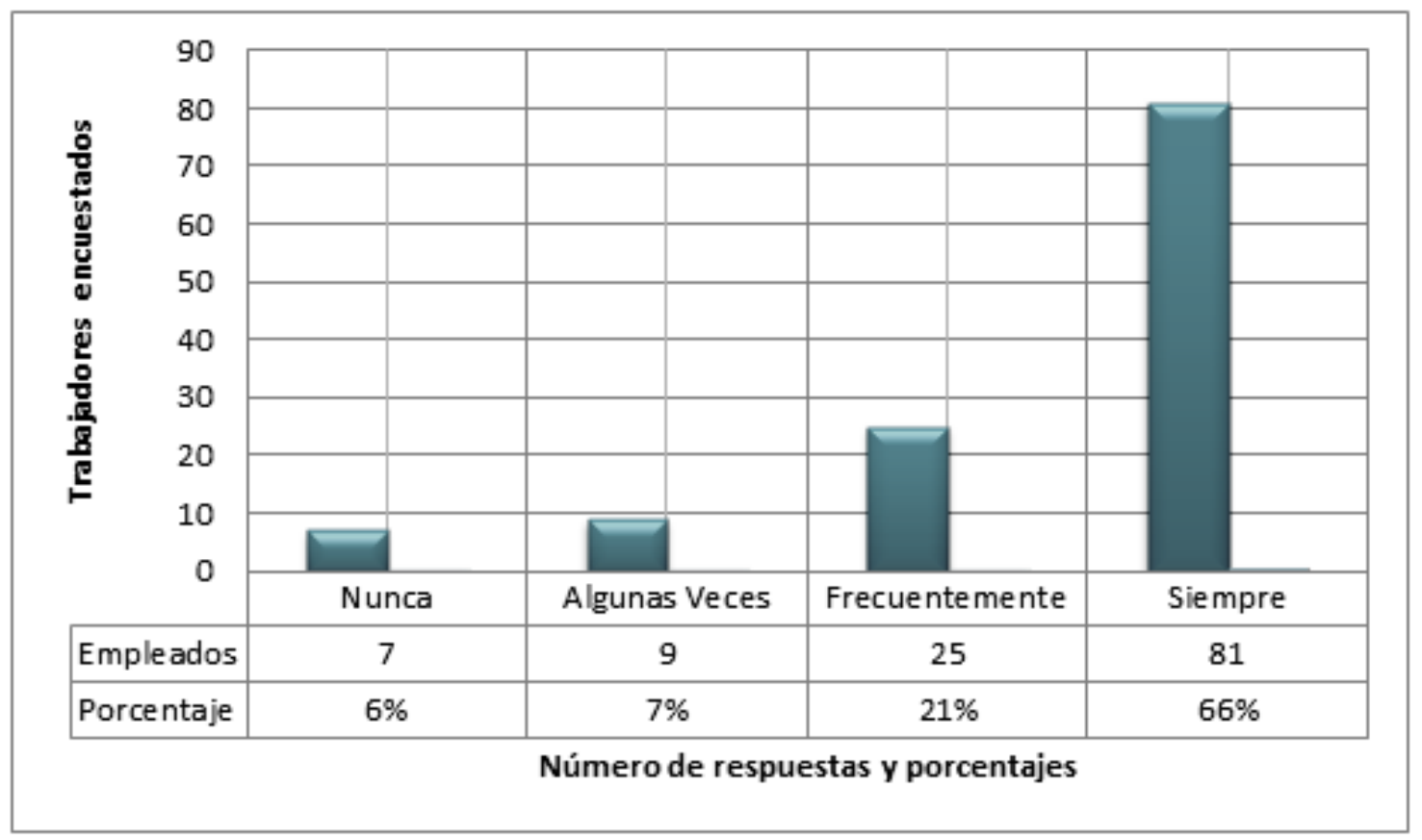

Fuente: Elaboración propia.

Lo que muestra la gráfica 9 , es que un $66 \%$ de los colaboradores de la constructora CARMOR siempre se sienten satisfechos con el puesto que tienen, mientras que un $21 \%$ creen que frecuentemente tienen ese sentimiento. El $7 \%$ piensan que algunas veces y solamente el $6 \%$ expresa que nunca está presuntuoso con su labor realizada. Muñoz (1990), define la satisfacción laboral como el sentimiento de agrado o positivo que experimenta un sujeto por el hecho de realizar un trabajo que le interesa, en un ambiente que le permite estar a gusto, dentro del ámbito de una empresa que le resulte atractiva y por el que percibe una serie de compensaciones acordes con sus expectativas. El éxito de una organización depende del desempeño de sus empleados, y por lo tanto, los trabajadores que expresan satisfacción son trabajadores productivos. La constructora debe obtener la perspectiva que necesita para asegurarse de estar haciendo todo lo posible para mantener al personal satisfecho y con su mejor desempeño. A pesar de que los otros porcentajes son bajos; deben de considerarse dentro de la empresa, puesto que existe algún motivo que esté dando estas manifestaciones de los empleados, al no sentirse a gusto con su puesto y poder conocer la postura de ellos para que ese sentimiento pueda reducirse. 
Figura No. 10 Satisfacción de necesidades básicas por el trabajo desempeñado

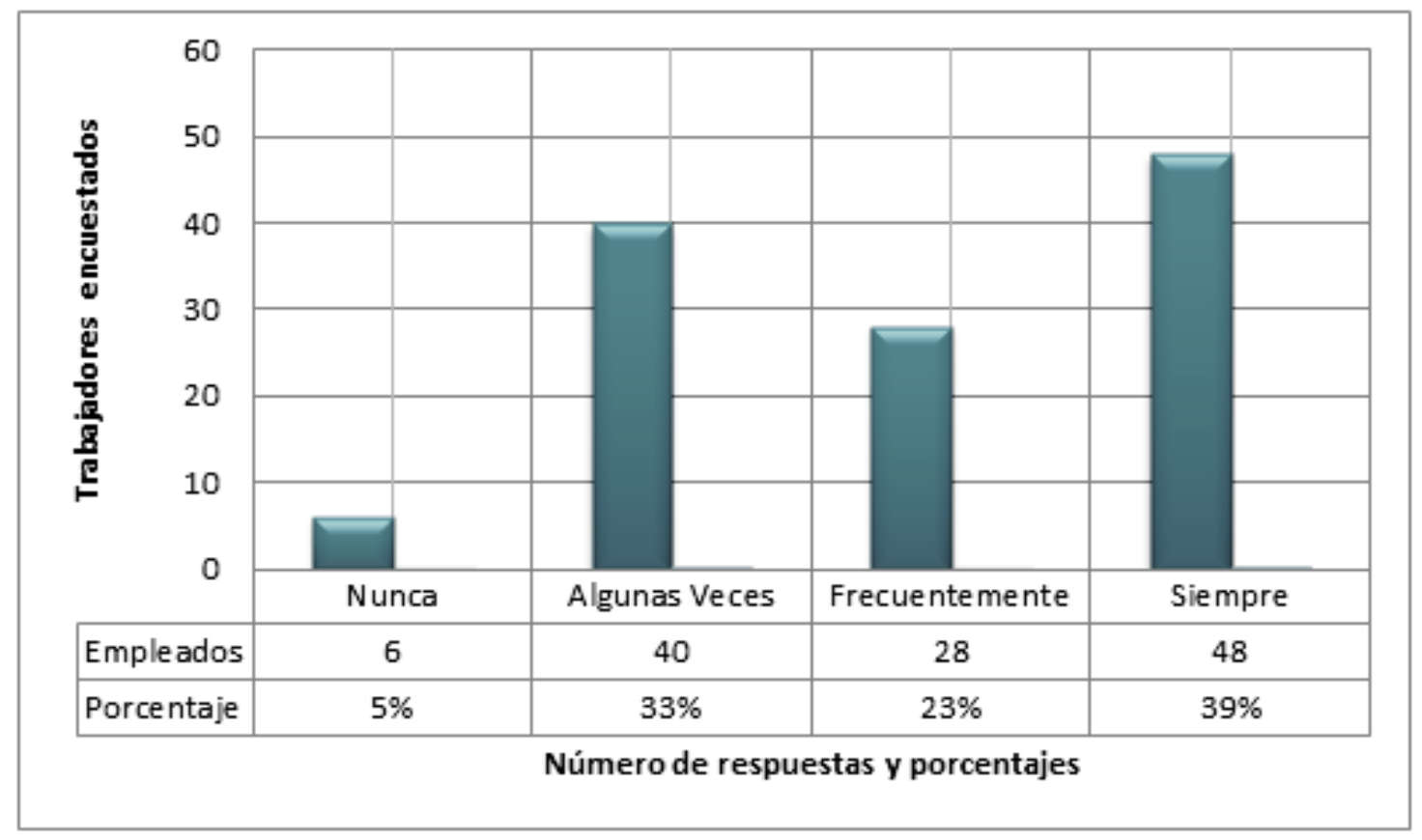

Fuente: Elaboración propia.

La gráfica 10 muestra efectivamente que solamente un 39\% siempre puede sentirse capaz de expresar que su trabajo en la constructora, le permite satisfacer sus necesidades. El $23 \%$ expresan que frecuentemente pueden obtener lo necesario; otro $33 \%$ piensan que algunas veces lo hacen, mientras que un $5 \%$ enmarca que nunca lo hace. Existen algunas teorías importantes alrededor de la motivación, como la teoría de la jerarquía de las necesidades, donde Maslow (1991), describe la importancia de suplir las necesidades básicas para posterior a ello, suplir las necesidades de orden superior, lo cual determina comportamientos en la conducta del ser humano, el cual trabaja por necesidad y no siempre por deseo. El enfoque en esta situación, es que los empleados no siempre se sienten motivados a trabajar como se espera, y aunque un bajo porcentaje expresa que nunca siente esa satisfacción, está presente y existe dentro de la empresa, sabedores que tienen otras necesidades que no logran satisfacer; provocando en cierta manera, un bajo rendimiento laboral que puede ser negativo para la productividad y el alcance de las metas propuestas. 
Figura No. 11 Formación necesaria para el desempeño de labores

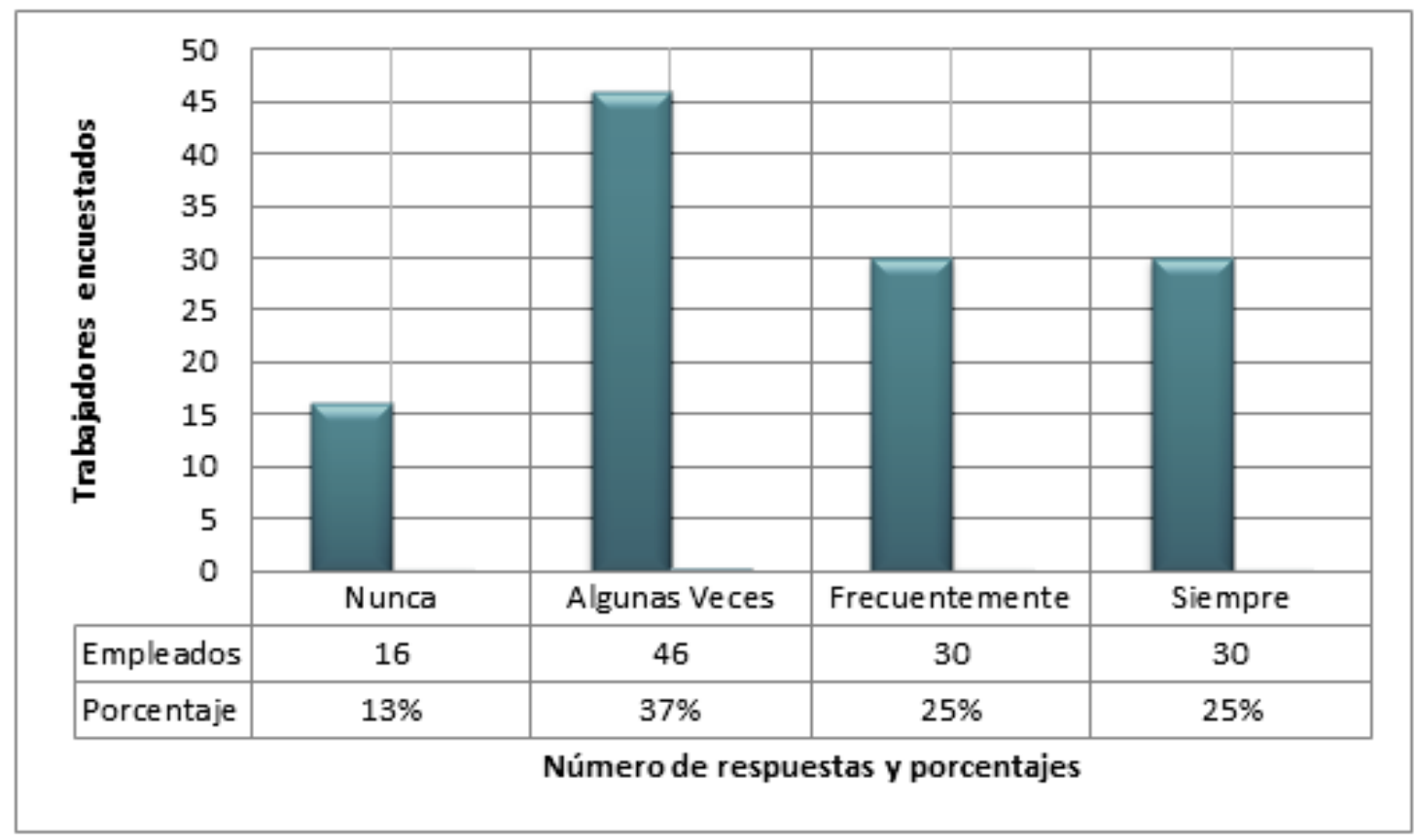

Fuente: Elaboración propia.

De acuerdo con los datos que muestra la gráfica 11 , se puede observar que el $25 \%$ de los empleados consideran que siempre los capacitan para desempeñar el trabajo, otro $25 \%$ opinan que frecuentemente reciben alguna inducción; mientras que un $37 \%$ expresan que en algunas veces las han recibido y el $13 \%$ afirman que nunca han tenido una formación para el desempeño de sus labores. Conversando directamente con algunos colaboradores, indicaron que en muchas ocasiones son los directivos quienes les brindan inducción de cómo realizar adecuadamente sus funciones. Como lo hacen ver Robbins y Judge (2009), el trabajo de una persona es más que solo realizar las actividades obvias, como ordenar papeles en la oficina o hacer el trabajo de campo; los trabajos requieren interactuar con los compañeros y jefes, seguir las reglas y políticas organizacionales, cumplir estándares de desempeño y estar en condiciones adecuadas. Deben existir mejoras en la constructora para que el trabajo permita satisfacer las necesidades de los empleados, en vista que es significativo tener en cuenta que ellos siempre buscan un crecimiento individual al lograr resultados y así tener oportunidades, pero para esto se deben recibir inducciones pertinentes y periódicas para un desarrollo laboral eficiente. 
Figura No. 12 Evaluaciones para conocer las necesidades de los trabajadores

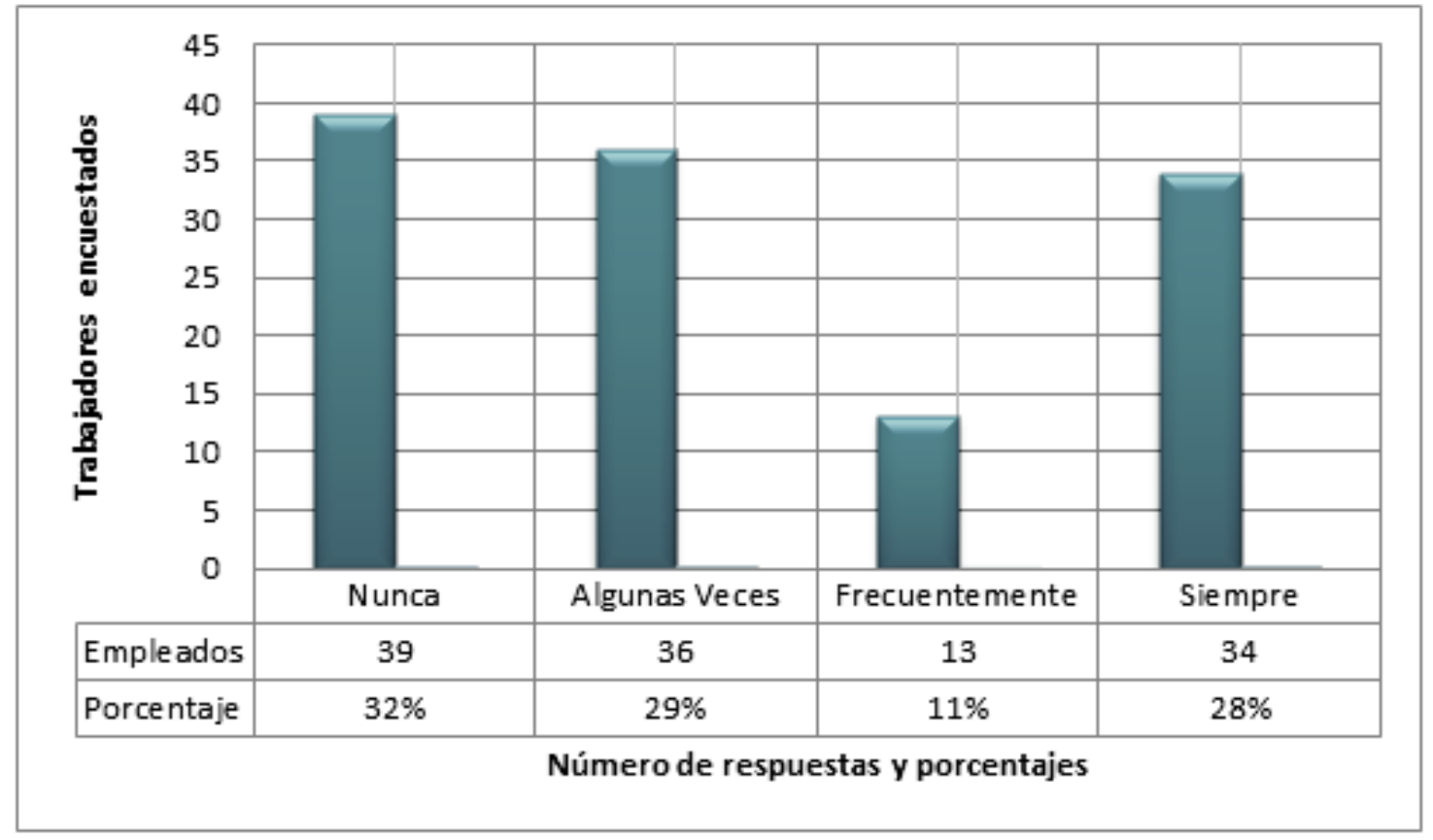

Fuente: Elaboración propia.

La opinión de los empleados en cuanto a si la empresa evalúa sus necesidades, la gráfica 12 muestra que el $28 \%$ de ellos expresan que siempre se han dado, el $11 \%$ opina que frecuentemente han observado estas actitudes; un $29 \%$ dicen que en algunas veces y un considerable $32 \%$ afirma que nunca han sabido de evaluaciones durante su estancia en la empresa. Robbins y Judge (2009), describen que la satisfacción laboral es un sentimiento positivo acerca de un puesto de trabajo que surge de la evaluación de las características. Por tal razón, es de importancia lo que se indica respecto a que las funciones y responsabilidades del puesto de trabajo estén bien establecidas, lo cual muestra que los directivos no brindan inducción del perfil ni del puesto con tanta claridad, y tampoco lo tienen definido, que ocupaciones y compromisos tiene cada integrante del equipo de trabajo. Debe mencionarse también, que el dueño y gerente general, siempre es la persona encargada de tomar las decisiones, no siempre está presente en la constructora y mucho menos compartiendo con los trabajadores de campo, lo que influye en ellos para entender realmente a que se refieren las evaluaciones en cuestión. La información de las necesidades de los empleados llega por los encargados de cada departamento, pero no puede considerarse como una evaluación en general. 
Figura No. 13 Influencia de la satisfacción laboral en la productividad

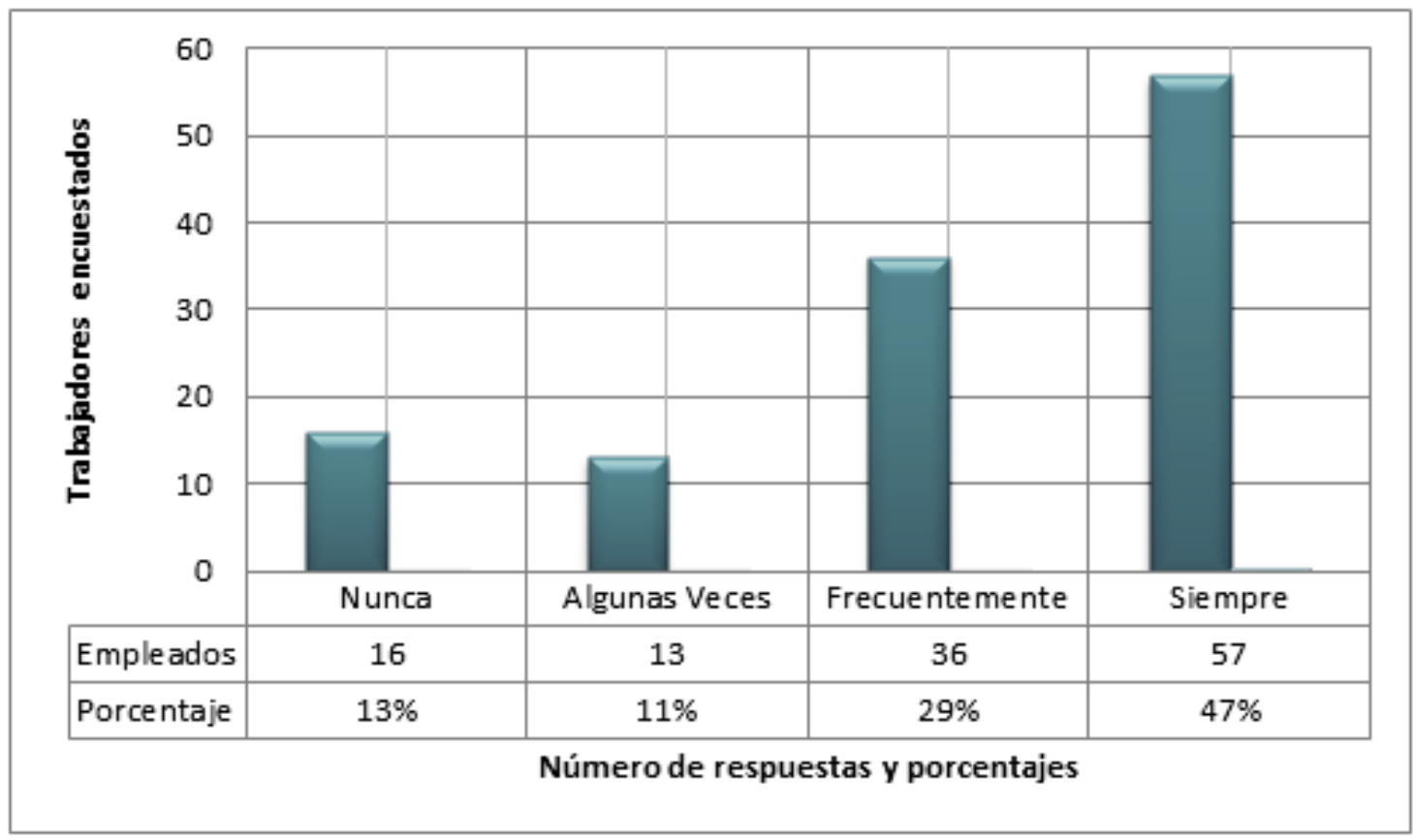

Fuente: Elaboración propia.

En lo que respecta a satisfacción y productividad, la gráfica 13 señala que el $47 \%$ de la población mostró que siempre se da este sentimiento dentro de la constructora, mostrando que, si el personal se encuentra satisfecho y motivado, rendirá productivamente. También hay un $29 \%$ que frecuentemente se encuentra satisfecho del trabajo que realiza mostrando resultados satisfactorios. No obstante un $11 \%$ manifiesta que algunas veces pueden manifestar satisfacción, y el $13 \%$ dice que nunca se sienten satisfechos; sin embargo, realizan su trabajo para producir tanto en cantidad como en calidad. En este aspecto, Davis y Newstrom (2003), identifican la satisfacción laboral, como el resultado de factores tanto internos como externos, en los que se puede mencionar la vida familiar y el trabajo y la relación que existe entre ellos. Así, pueden señalarse la motivación, el desarrollo profesional del personal, la pertenencia e identificación en la organización y la productividad que es una relación entre eficiencia y eficacia en la ejecución del trabajo individual y organizacional. La satisfacción laboral en los empleados es de suma importancia, sobre todo para la productividad y el logro de objetivos de la constructora, pues cada uno debe de estar conforme en el área donde desempeña su trabajo; de lo contrario pueden generar cierto fracaso en la empresa. 
Figura No. 14 Presencia de razones o causas que desmotivan a los empleados

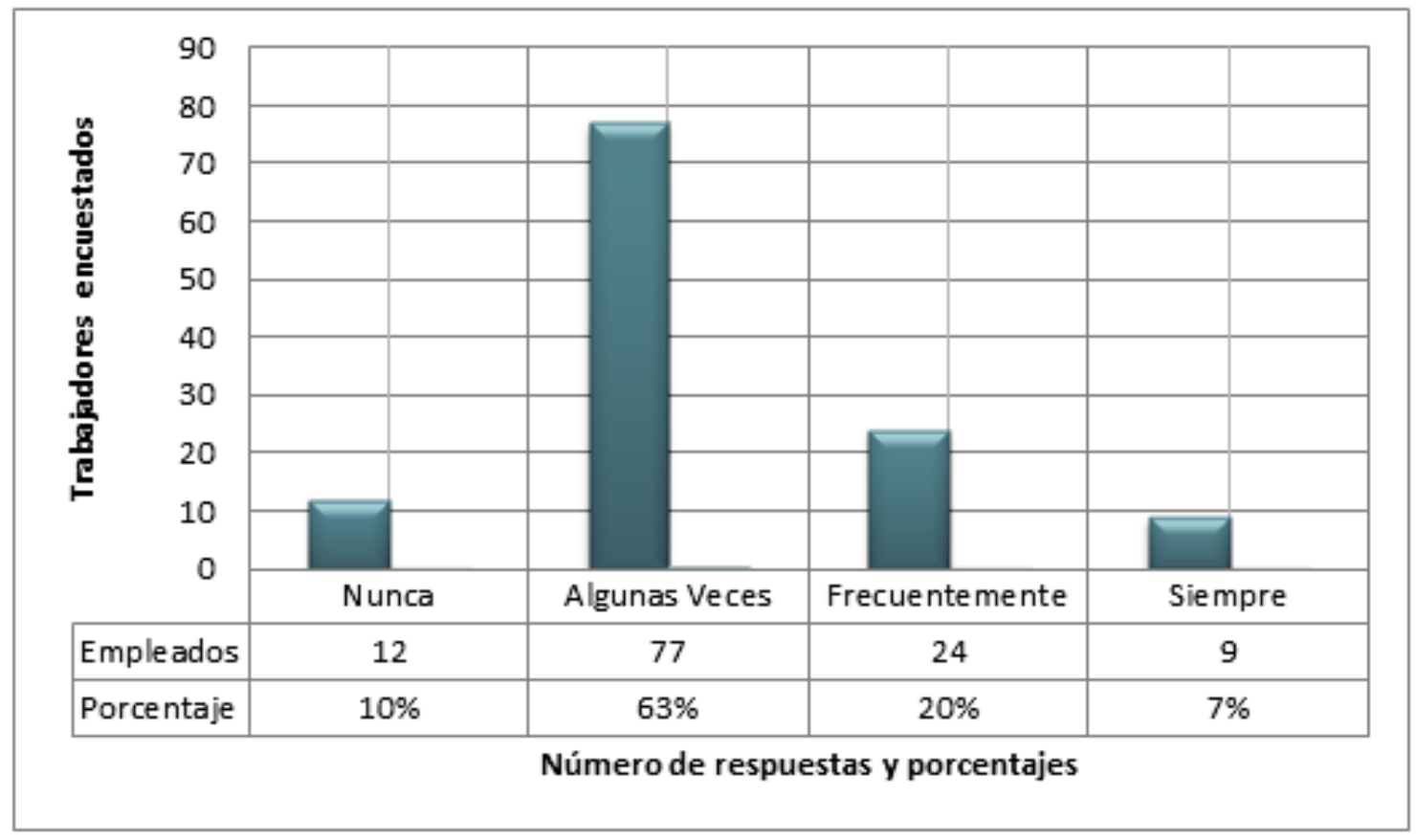

Fuente: Elaboración propia.

Con los datos de la gráfica 14 , se determinó que el $7 \%$ cree que siempre existen razones que desmotiven, un $20 \%$ manifestó que frecuentemente se viven estas situaciones de desmotivación. El $63 \%$ de la población establece que a veces existen causas que los desmotivan para realizar su trabajo con eficiencia, lo que provoca un desequilibrio en relación al clima laboral dentro de la constructora. El 10\% opina que nunca se dan estas razones. En estas circunstancias, Kreitner y Kinicki, (1997), establece que la motivación representa a todo el proceso psicológico que provoca la estimulación en las personas, lo que representa acciones voluntarias, persistencia y sobre todo, dirección hacia los objetivos. Una de las principales causas que desmotivan a los empleados dentro de la constructora, es la falta de incentivos de diferentes tipos, y a la vez, no brindarles apoyo en relación a las jornadas de trabajo. Otra causa, es la situación de contrataciones de trabajo, pues no siempre los trabajadores de campo son ingresados en la planilla correspondiente y en ocasiones deben de trabajar horas extras y los siete días a la semana. No puede lograrse que los colaboradores realicen su trabajo con esfuerzo si no reciben la motivación necesaria. 
Figura No. 15 Considerar la búsqueda de otro trabajo

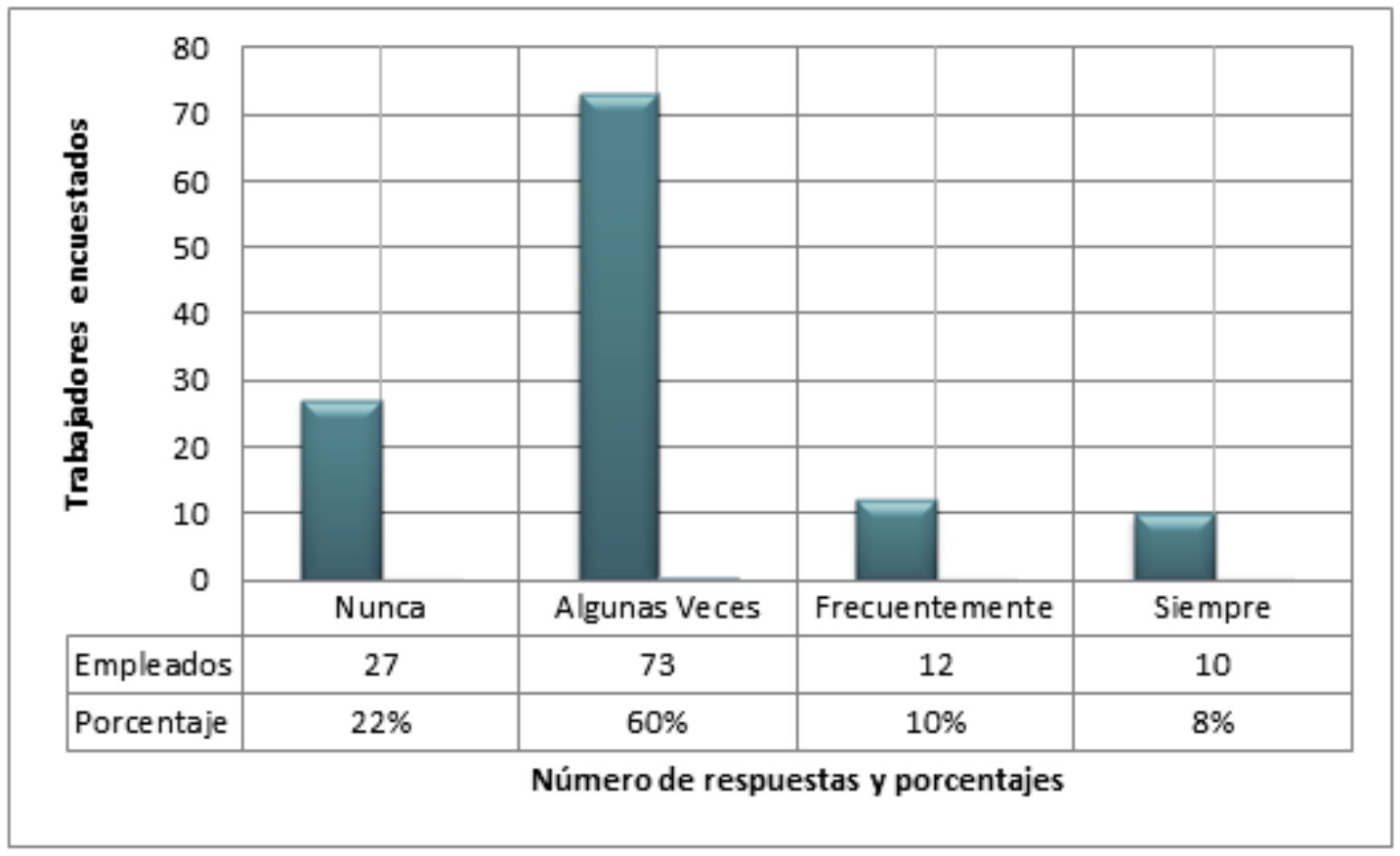

Fuente: Elaboración propia.

Los datos que se reflejan en la gráfica 15 , es que el $8 \%$ de los empleados, siempre considera buscar otro empleo, el $10 \%$ frecuentemente lo ha pensado; mientras que un $60 \%$ algunas veces ha considerado buscar otro trabajo, y un $22 \%$ nunca ha pensado en esa opción. Parecen porcentajes pequeños de quienes consideran esta opción, pero son datos que existen y están dentro de la organización. Sherman (1994), indica que las relaciones con los supervisores, injusticia en las revisiones de evaluación de desempeño y el clima laboral, son causas del por qué se van los trabajadores. Según lo establecido con los empleados con quienes se obtuvo la información, comparten (especialmente los de campo) que por no tener una plaza fija dentro de la empresa, siempre consideran o tienen otras opciones a la mano, en caso de que no puedan continuar en un proyecto, puesto que las necesidades personales siempre están presentes. Mientras que el personal de oficina o mecánicos, que tienen más tiempo laborando en la empresa, poseen un puesto estable dentro de la constructora, por lo que no consideran buscar otro trabajo. 
Figura No. 16 Valores en porcentajes por variables

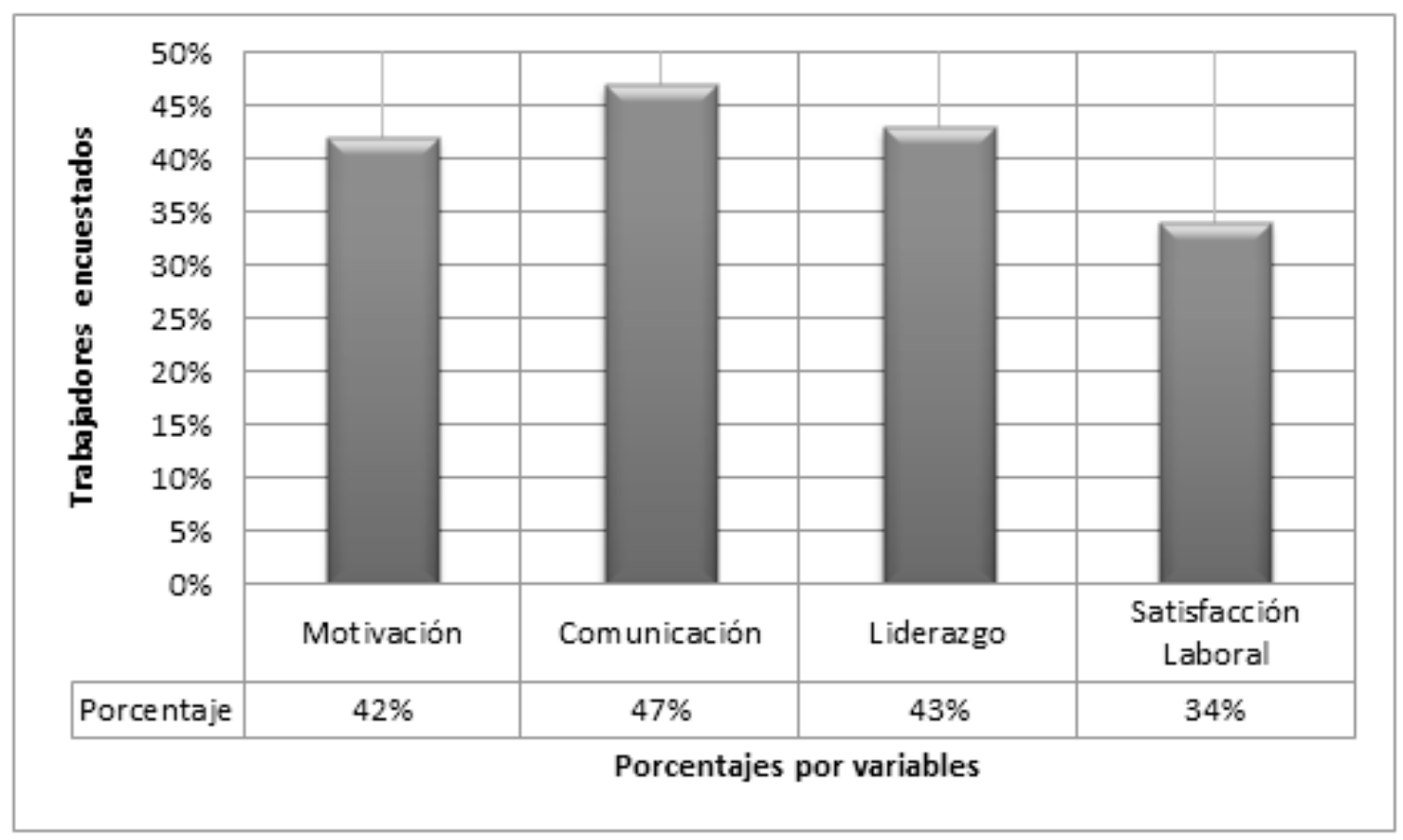

Fuente: Elaboración propia.

Según Gan (2007), el clima laboral de Likert mide las variables de motivación, comunicación, liderazgo y satisfacción laboral. En el caso de la empresa constructora CARMOR, puede comprobarse en cuanto a la motivación, que el $42 \%$ son quienes se sienten con entusiasmo dentro de la empresa al realizar sus labores. La comunicación puede decirse que ocupa el nivel más alto, con un $47 \%$, a pesar que en ocasiones, los empleados sienten que sus opiniones no cuentan en el momento de tomar decisiones. El liderazgo que se desarrolla en la constructora llega al $43 \%$, con lo que puede observarse una notable falta de organización dentro de la empresa y el manejo del personal.

En cuanto a la satisfacción laboral, que es el porcentaje más bajo con un $34 \%$, puede resaltar el punto, en que no todos los empleados realmente están satisfechos con lo que el empleo representa en su satisfacción; recordando que varios de los trabajadores consideran o piensan la opción de otro trabajo; situación que puede en alguna medida, perjudicar la productividad de la constructora, puesto que no todos los colaboradores se sienten satisfechos con lo que reciben por su labor. Puede entonces consolidarse que, la parte motivacional y de satisfacción dentro de los empleados de la constructora influye potencialmente en los porcentajes que se observan, lo que debe considerarse para que dentro de la organización pueda mejorar el clima laboral para un excelente funcionamiento de la misma. 


\section{Discusión}

En los resultados encontrados en la investigación aplicada a la constructora, puede observarse que respecto a los miembros de la empresa, tanto en trabajadores administrativos y personal obrero, existe un bajo porcentaje de satisfacción en el trabajo, a pesar que la mayoría viene laborando por varios años; es evidente que muchos expresaron no estar completamente a gusto con su labor desempeñada, por lo que la constructora trata de tener en cuenta su estabilidad, pero falta priorizar actitudes fundamentales en los trabajadores, como la dedicación al trabajo, el compromiso organizacional y un estado de ánimo en el trabajo, los cuales repercutirán en que los trabajadores puedan producir y rendir efectivamente en sus labores.

En el caso de los reconocimientos o incentivos que los jefes pueden brindar a sus empleados por su desempeño, muchos colaboradores manifiestan que no reciben esta clase de actitudes por parte de sus superiores, lo cual representa que el trabajador no se identifique con la empresa y que solamente la busque como una fuente de ingreso para el bienestar de su familia. Es bien sabido que la motivación es un factor importante para el buen desempeño de los trabajadores, por lo que la empresa debe considerar, que si desea generar la mejor productividad y mayor desempeño, debe mejorar la satisfacción de sus colaboradores, pensando en sus necesidades para que ellos puedan sentirse parte de la empresa y dar lo mejor de sí.

Sobre la comunicación se determinó que no en todas las ocasiones puede definirse como eficiente, por lo que podría generar problemas en la consecución de los objetivos tanto a corto, como a largo plazo de la constructora.
Además, la falta de comunicación influye en las relaciones personales, lo que puede perjudicar el desarrollo de la empresa y no alcanzar la competitividad de la misma. Los supervisores no siempre generan un adecuado ambiente de confianza que vaya relacionado con la manera de proponer decisiones a los responsables de cada área de trabajo, entablando una comunicación efectiva.

En relación con la información recolectada que tuvo como finalidad identificar los aspectos considerados para el liderazgo y la toma de decisiones en los diferentes niveles de la organización, se pudo determinar que estos son aceptables, lo cual indica que existe un respaldo de los altos niveles para el pro y mejoramiento de las actividades, así como también se consideran admisibles las decisiones que se toman por parte de los jefes y que existe una participación efectiva por parte de los colaboradores en el desarrollo de nuevos procesos y alternativas de mejora. Se hace la salvedad, que un buen porcentaje ha considerado buscar otras opciones, pues la satisfacción laboral no siempre creen que es la más adecuada, pero que se acepta porque es fuente de trabajo y sostenimiento familiar.

La constructora CARMOR hasta el momento, no cuenta con evaluaciones sobre el clima laboral ni necesidades de los empleados dentro de la empresa, lo que es indispensable para la obtención de datos relevantes sobre el ambiente profesional actual, para poder lograr una mejora en las distintas áreas de trabajo; por lo que esta investigación, ayuda para estar al pendiente de las situaciones que se viven y se avecinan dentro de la empresa, y llegar a alcanzar de la mejor manera posible, los objetivos propuestos. 


\section{Conclusiones}

El clima laboral dentro de la empresa Constructora CARMOR es parcialmente favorable, según los datos obtenidos sobre los distintos factores evaluados, en las escalas de: siempre, frecuentemente, algunas veces y nunca; dando los porcentajes en motivación con un $42 \%$, comunicación con un $47 \%$, liderazgo con un $43 \%$ y satisfacción laboral con un $34 \%$; observando una baja considerable en el aspecto de satisfacción en los empleados.

Se identificó que la motivación no siempre es buena por parte de la gerencia y los colaboradores en la empresa, aunque sí se estableció un alto prestigio para la organización por parte de los colaboradores. No reciben una constantes motivación proactiva por parte del jefe, o en algunas ocasiones incentivos no económicos; pero sí una satisfacción por parte de los colaboradores en su área de trabajo y también con sus compañeros de labor.

La comunicación en la constructora es aceptable, de acuerdo a la escala evaluada en cuanto a los canales de comunicación formal e informal, en donde se estableció que prevalece la comunicación verbal en los niveles en cuanto a la escrita, existiendo una retroalimentación acertada, considerando la asignación de actividades como justas y tienen definidos los objetivos a cumplir, brindando una ordenada toma de decisiones por parte del jefe y sus colaboradores; siempre teniendo en cuenta que las decisiones de mayor importancia son tomadas por los niveles superiores. La satisfacción laboral de los empleados es el factor más bajo encontrado en la investigación del clima laboral en la constructora con un $34 \%$, aspecto que tiene que ver en cuanto a que el personal obrero (que es la mayoría con 117 empleados), son quienes no tienen las mismas prestaciones e incentivos económicos y/o de otra índole, así como también, sus jornadas y horarios laborales son distintos y más amplios que los de otros departamentos. Estos contextos son los que vienen a afectar la satisfacción de los colaboradores en torno a su situación salarial, que provocan esta baja emocional y puede en gran parte afectar a la productividad de la empresa, al tomar ellos su empleo como algo meramente necesario para subsistir.

\section{Referencias}

Adler, R. (2005). Comunicación Organizacional. Principios y Prácticas para negocios y Profesionales. (Octava Ed.) McGraw Hill Interamericana. México, D.F.

Amoros, M. (2007). Calidad de vida en el trabajo. Ed. Libreros Unidos. Maracaibo, Venezuela.

Ardouin, et al., (2000). Diseño organizacional. Organización y métodos para la excelencia. CECSA. México, D. F.

Blanchard, K. (2000). El Ejecutivo al minuto en forma. Edit. MacGraw-Hil. Barcelona, España.

Carretón, C. (2007). Las relaciones públicas en la comunicación interna de la Banca española. España (España): Netbiblo.

Chiavenato, I. (2009). Comportamiento organizacional. La dinámica del éxito en las organizaciones. $2^{\mathrm{a}}$. Edit. McGraw Hill. Bogotá, Colombia.

Cimpa, D. (1990). Liderazgo industrial. $2^{\mathrm{a}}$. Edición. Editorial: Legis. Bogotá, Colombia.

Davis, K. y J. Newstrom (2003). Comportamiento humano en el trabajo. $11^{\mathrm{a}}$. Ed. México: McGraw- Hill. 
Dessler, G. (2009). Administración de recursos

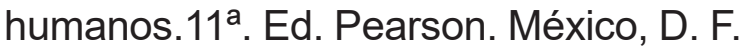

Espinoza, M. (1999). Líderes del Tercer Milenio. Edit. EDIAS. Lima, Perú.

Gan, F. (2007). Manual de recursos humanos. Edit. UOC. Barcelona, España.

García, S. (2007). El clima laboral depende sobre todo del jefe. Tesis Doctoral, Universidad de Granada. México, D.F.

García, J. (2011). Comunicación Interna. Madrid (España): Díaz de Santos.

James, E. y W. Lindsey (2008). Administración y control de la calidad. Edit. Thomson. México, D. F.

Katz, D. y R. Kahn (1989). Psicología social de las organizaciones. Trillas, $2^{\mathrm{a}}$. Ed. México, D. F.

Kreitner, R. y A. Kinicki, (1997). Comportamiento de las ornganizaciones. Madrid (España) McGraw-Hill.

Lado, A. y M. Wilson, (1994). "Human resource systems and sustained competitive advantage: A competency-based perspective". Academy of Management Review. 19, 4 ABI/INFORM. Global pg. 699.

Landy, F. y J. Conte (2005). Introducción a la psicología industrial y organizacional. McGraw Hill. México, D. F.

Maslow, A. (1991). Motivación y personalidad. Días de Santos S. A. Casa de Libro. Madrid, España.

McGregor, D. (1966). The human side of Enterprise, Leadership and motivation. Cambridge. The MIT Press. Reino Unido.

Méndez, C. (2006). Clima organizacional en Colombia El IMCOC: Un método de análisis para su intervención. Colección de lecciones de administración. Bogotá: Universidad del Rosario de Colombia.
Mitchell, T. (1997). "Matching motivational strategies with organizational contexts". In L.L. Cummings and B. M. Staw (Eds.), Research in organizational behavior. Vol. 19, 57-149. Greenwich, CT: JAI Press Inc. 1997.

Montes, R. (2006). Relaciones interpersonales en el trabajo. Editorial Merced. California.

Muñoz, A. (1990). Satisfacción e insatisfacción en el trabajo. F. de Psicología. Universidad Complutense, Madrid, España.

Robbins, S. (1999). Comportamiento Organizacional. McGraw-Hill Interamericana. México D. F.

Robbins, S. y M. Coulter (2005). Administración. Octava Edición. Pearson Educación. México, D. F.

Robbins, S. y T. Judge (2009). Comportamiento Organizacional. Decimotercera Edición. Pearson/Prentice Hall. México.

Rodríguez, A. y A. Bakker (2011). El Engagement en el Trabajo. Editorial Erasmus. Madrid, España.

Sallenave, J. (1994). La gerencia integral. Editorial Norma. Bogotá, Colombia.

Sherman, B. (1994). Administración de Recursos Humanos. 10 ${ }^{\mathrm{a}}$. Edición. South Western College Publishing, Cincinnati, Ohio, EUA.

Torres, A. y E. Agulló, (2002). "Calidad de vida laboral: hacia un enfoque integrador desde la Psicología Social". Psicothema. ISSN 0214 - 9915 CODEN PSOTEG. Vol. 14. N ${ }^{\circ} 4$, pp. 828-836. 


\section{Sobre autor}

\section{Hugo Jovany Aragón González}

Tiene una Maestría en Gerencia Administrativa de Recursos Humanos, en el Departamento de Estudios de Postgrado, USAC, CUNSURORI, Jalapa, 2019. Es Licenciado en Pedagogía y Desarrollo Educativo, en la Facultad de Ciencias de la Educación, Universidad Panamericana, sede Jalapa, 2016. Posee un Profesorado Universitario en Educación con Especialidad en Didáctica de la Comunicación y la Matemática, en la Facultad de Ciencias de la Educación, Universidad Panamericana, sede Jalapa, 2014. Es Maestro de Educación Primaria Urbana. Posee Diplomados Universitarios en Educación y Tecnología. Ha trabajado como Locutor, Docente Universitario, Docente en el Nivel Medio, Ciclo Básico y como Maestro de Primaria. Ha sido facilitador en conferencias, talleres y capacitaciones a otros docentes.

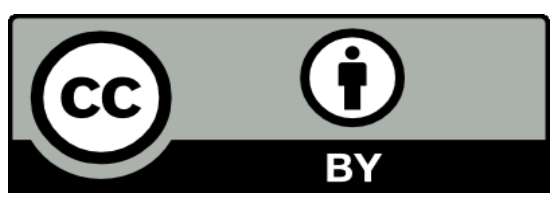

Este texto está protegido por una licencia CreativeCommons 4.0.

Esta licencia permite que otros distribuyan, mezclen, adapten y desarrollen su trabajo, incluso comercialmente, siempre y cuando le den crédito por la creación original. 